\title{
PMS-SIM: O SIMULADOR EDUCACIONAL EM GESTÃO DE PROJETOS
}

\author{
PMS-SIM: THE EDUCATIONAL SIMULATOR IN PROJECT MANAGEMENT
}

\author{
Murilo Alvarenga Oliveira \\ Doutor em Administração - FEA-USP \\ Universidade Federal Fluminense - UFF \\ Programa de Pós-graduação em Administração (PPGA) \\ Volta Redonda, Rio de Janeiro - Brasil \\ malvarenga@id.uff.br
}

Eduardo de Lima Pinto Carreiro Mestre em Administração MPA-PPGA-UFF Centro Universitário de Volta Redonda - UNIFOA Volta Redonda, Rio de Janeiro - Brasil eduardolpcarreiro@gmail.com

Humberto Reis dos Santos Souza Mestre em Administração MPA-PPGA-UFF Instituto Federal de Educação, Ciência e Tecnologia do Rio de Janeiro - IFRJ Resende, Rio de Janeiro - Brasil humberto.souza@ifrj.edu.br

Resumo

O relato técnico tem como objetivo analisar a trajetória do desenvolvimento de um simulador educacional (PMS-Sim) e sua aplicação num processo longitudinal (seis anos) em ambientes acadêmicos e profissionais. Dessa forma, a abordagem orientadora para o desenvolvimento analítico da solução ocorreu em três estágios e com triangulação multimétodo, técnica que combina dados e informações de meios específicos de pesquisa. Os estágios foram: (1) levantamento de opinião com análise quantitativa, (2) procedimentos mistos na adaptação acadêmica, e (3) levantamento de opinião e pesquisa qualitativa com participantes de incubadoras de empresas. Os resultados de cada um dos estágios permitem indicar o auxílio do sistema para a capacitação em gerenciamento de projetos, pois profissionais da área, num ambiente organizacional, relevaram a contribuição em vivenciar de forma segura as fases de um projeto; já em ambientes acadêmicos, alunos e docentes evidenciaram avanços do conhecimento em gestão de projetos. Para ambientes de inovação permitiu-se que o participante praticasse elementos de gestão de projetos dentro de uma empresa incubada.

Palavras-chave: Simulador educacional. Gestão de projetos. Aprendizagem vivencial. Educação gerencial.

\section{Abstract}

The technical report aims to analyse the development trajectory of an educational simulator (PMS-Sim) and application through a longitudinal process (six years) in academicprofessional environments. Thus, a guiding approach to the analytical development of the 
solution occurred in three stages and with multimethod triangulation, a technique that mixes data and information from specific research paths. The stages were: (1) opinion survey with quantitative analysis, (2) mixed procedures in academic adaptation, and (3) opinion survey and qualitative research with participants from business incubators. The results of each of the internships indicate the help of the system for training in project management, as professionals in the area in an organizational environment have highlighted the contribution to safely living as phases of a project; already in academic environments, students and teachers evidenced advances in knowledge in project management. For innovation environments, if the participant practices elements of project management within an incubated company.

Key-words: Educational simulator. Project management. Experiential learning. Business management education.

\section{Cite como - American Psychological Association (APA)}

Oliveira, M. A., Carreiro, E. de L. P., Souza, H. R. dos S., \& Dias, J. A. da S. (2020, set./dez.). PMS-Sim: o simulador educacional em gestão de projetos. Revista de Gestao e Projetos (GeP), 11(3), 185-217. Relatos Técnicos. https://doi.org/10.5585/gep.v11i3.18216.

\section{Introdução}

O desenvolvimento tecnológico tem causado mudanças de hábitos e de comportamentos tanto na sociedade como nas empresas, principalmente nas tradicionais, devido às alterações de processos e de produtos (Perides, Vasconcellos, \& Vasconcellos, 2020). Para que as empresas alcancem os objetivos estabelecidos e criem as modificações necessárias, neste novo ambiente, é de fundamental importância a Gestão de Projetos.

Desse modo, a educação em Gestão de Projetos tem exigido foco nas habilidades, conhecimentos e competências, bem como no exercício da prática, que deve ser tratado com a mesma relevância que o ensino convencional (Cicmil \& Gaggiotti, 2018; Schmitz, Alperstedt, Van Bellen \& Schmitz, 2015). Sendo assim, para que os objetivos estabelecidos em um projeto sejam atingidos, há necessidade de que os gestores sejam educados para as técnicas adequadas de gerenciamento de projetos (Bukvić, Buljubašić, \& Ivić, 2020; Bell, 2016).

Os processos educacionais na área, nos últimos anos, geraram o interesse pelo uso de jogos sérios, como os jogos de empresas, para educação e gestão de projetos (Calderón, Ruiz, \& O’Connor, 2018). Posto isso, as estratégias vivenciais dos jogos de empresas e a aprendizagem baseada em jogos (gamificação) vêm sendo aplicadas com sucesso em alguns ambientes educacionais e cada vez mais adotadas nos cursos universitários (Barbosa \& Rodrigues, 2020) e em ambientes empresariais (Carreiro \& Oliveira, 2015).

Logo, percebe-se que a formação usual em projetos prioriza o ensino da teoria e das 
técnicas e tem como foco principal a fase de iniciação e planejamento, bem como técnicas de controle e encerramento, contudo a principal fase do projeto não é desenvolvida, a execução (Carreiro \& Oliveira, 2018; Patah et al., 2016; Schmitz et al., 2015). Neste sentido, um problema evidenciado na área seria a formação em projetos voltada para o ensino convencional e que circunscreve ou prioriza a fase do planejamento em detrimento das estratégias vivenciais com o ciclo de vida completo de um projeto.

Para tanto, o relato técnico tem como objetivo analisar a trajetória do desenvolvimento de um simulador educacional (PMS-Sim) e sua aplicação num processo longitudinal (seis anos) em ambientes acadêmicos e profissionais. Em 2012, iniciou-se o desenvolvimento do Project Management Simulation (PMS-Sim), simulador desenvolvido para auxiliar a dinâmica de jogo de empresas em Gestão de Projetos para atender uma empresa automobilística para formação prática na área (Carreiro \& Oliveira, 2015). Posteriormente, desenvolveu-se, com o uso do PMS-Sim, um Programa Vivencial em Gestão de Projetos (PVGP), com o intuito de desenvolver a dinâmica em ambientes universitários (Carreiro \& Oliveira, 2018; Dias, 2017; Carreiro, 2016). Atualmente, em uma segunda versão, adaptou-se o simulador para dinamizar um jogo de empresas para incubadoras de base tecnológica (Souza, 2019).

\section{Referencial teórico}

Esta seção aborda os fundamentos teóricos do relato, apresentando uma reflexão sobre o panorama atual da gestão de projetos com destaque para a formação prática do gestor, por isso o conteúdo discutido se complementa com o uso da estratégia de aprendizagem vivencial, denominada jogo de empresas, como uma alternativa viável para a gestão de projetos.

\subsection{Panorama atual da Gestão de Projetos}

Abordam-se projetos não é de hoje, e, mesmo de forma leiga, todos nós temos nossos projetos, sendo que o objetivo da gestão de projetos é a entrega bem-sucedida de requisitos complexos, ou seja, dentro do orçamento estipulado, do prazo acordado, e com a qualidade aceitável (Dziekoński, 2017; Ramazani \& Jergeas, 2015; Ashleigh et al, 2012). Competências como liderança estão subdesenvolvidas em equipes de projetos, sendo uma das causas do elevado número de fracassos, mesmo os que são concluídos, mas violando o prazo, a qualidade, ou o escopo inicial (Chipulu, Ojiako, \& Ashleigh, 2011).

Percebe-se a necessidade de uma carga diferenciada de treinamento para os profissionais envolvidos com a atividade de gestão de projetos. Isso se justifica pelo aumento na complexidade no gerenciamento desses projetos, destacando-se três necessidades:

(i) conhecimentos técnicos;

(ii) habilidade de liderança e gestão; 
(iii) o desenvolvimento de pensamento crítico para lidar com ambientes complexos, sujeitos constantemente a mudanças (Ramazani \& Jergeas, 2015; Vierira \& Antoniolli, 2018).

Observa-se, na agenda tradicional de GP da literatura contemporânea, que é hora de parar de vender a disciplina de GP e adequá-la ao rigor conceitual da realização rígida de objetivos para intervenções isoladas. A construção de uma dimensão crítica do GP passa pelo exame contínuo e o objetivo da pertinência, realismo e resiliência das metas do projeto por meio de monitoramento e avaliação.

A ocupação principal do GP, apesar de seu interesse de longa data no tópico de sucesso do projeto, negligenciou uma das principais características do aprendizado organizacional e social: a avaliação (Picciotto, 2019).

Algumas das abordagens tradicionais de GP se concentram demasiadamente nas entradas e saídas sem muita atenção às entregas ou impactos no entorno. Os requisitos de comprometimento e aprendizado são observados através da aplicação de critérios de desempenho plausíveis, em vez da opção por indicadores de métricas complexas (Picciotto, 2019).

Como contraponto da visão clássica abordada, os métodos ágeis, que, por sua vez, enfatizam a necessidade da construção dinâmica do escopo com críticas recentes à teoria tradicional de GP, resultam em uma nova abordagem, denominada Gerenciamento Ágil (GAP). Um dos pressupostos dessa abordagem é o empirismo em decorrência das sucessivas iterações com o destinatário do projeto (Eder, Conforto, Amaral, \& Silva, 2015).

As premissas dos modelos ágeis indicam a melhoria contínua da área de GP com um conjunto de práticas e conceitos que se encaixam na nova realidade dos projetos, necessitando, dentre outras, de flexibilidade, de adaptabilidade e de agilidade. Essas características tornam o framework ágil um grande aliado durante o desenvolvimento de softwares, por exemplo, possibilitando a entrega de valor em menor prazo e dentro dos padrões de qualidade. Como fragilidade, evidencia-se o foco quase exclusivo nos processos de desenvolvimento do projeto, deixando áreas complementares em segundo plano (Vargas, 2016).

Neste sentido, outro alerta ao modelo puro sobressai quanto ao tamanho das equipes, indicando uma relação negativa entre o tamanho da equipe e a qualidade da entrega. Pode-se argumentar que equipes grandes coletam informações mais diversas do que equipes menores, e, portanto, possuem habilidades mais inovadoras. Esse benefício potencial, entretanto, é negado pela, também possível, complexidade da comunicação e falta de consenso. Além disso, à medida que o número de membros da equipe aumenta, as interfaces de coordenação se tornam um problema. O planejamento de sprint se torna mais difícil e complexo, demanda esforço extra para aplicar estratégias diversificadas, criar um entendimento amplo e intervir para controlar 
conflitos em potencial (Liu, Ho, Chang, \& Tsai 2019).

De maneira incremental, surgem os modelos híbridos, que associam as boas práticas do modelo tradicional de gestão de projetos, utilizados em cenários mais estáveis e com escopos bem-definidos, com as boas práticas do modelo ágil de gestão de projetos para cenários dinâmicos e flexíveis, como são os cenários do setor da Tecnologia da Informação. Destaca-se, também, a importância de uma análise crítica e ponderada quanto ao momento em que se deva aplicar (Silva \& Melo, 2016).

Desta forma, os profissionais podem apreciar a incorporação de fatores de sucesso do triângulo de ferro do GP tradicional durante o planejamento de cada iteração quando definirem os objetivos para essa iteração. A partir desses resultados, as equipes ágeis devem discutir funcionalidade, cronograma, qualidade e satisfação da equipe como objetivos em cada iteração. Também é possível e, até mesmo recomendável, incorporar o orçamento em sua discussão sobre o objetivo da iteração, desde que sejam incluídos membros adicionais à equipe com esta expertise (Drury-Grogan, 2014).

\section{2 Jogos de empresas e formação em gestão de projetos}

Os jogos de empresas para a formação gerencial em gestão de projetos permitem que o participante da vivência utilize ou aprenda novos conhecimentos e habilidades em um ambiente de prática (Carreiro \& Oliveira, 2015,
2018; Calderón, Ruiz, \& O’Connor, 2018; Law, 2019; Barbosa \& Rodrigues, 2020). Isso está em consonância com a Teoria da Aprendizagem Vivencial (ELT - Experiential Learning Theory), que entende o aprendizado como um ciclo recursivo mediado pela experiência, ou seja, o aprender fazendo (Kolb, Kolb, Passarelli, \& Sharma, 2014)

Isso pode ocorrer porque, não raro, os programas de formação em projetos contemplam apenas os limites do planejamento, deixando a aplicação para a atividade profissional, muito embora a formação em gestão de projetos enseje a prática (Carreiro \& Oliveira, 2018; Cicmil, \& Gaggiotti, 2018; Goedert, \& Najjar, 2017; Patah et al., 2016; Schmitz et al., 2015). Isso porque, o próprio PMI (Project Management Institute, 2017) cataloga em BoKs (Body of Knowledge) as melhores práticas em gestão de projetos no $\mathrm{PMBoK}$, por ser um dos principais institutos do campo (Hornstein, 2015; Carvalho \& Rabechini Jr., 2017).

\section{Método da produção técnica}

Para esta seção foi realizada uma descrição detalhada da solução desenvolvida para dinamizar o programa educacional de formação em gestão de projetos. Há o relato do desenvolvimento do simulador educacional, os profissionais envolvidos, os detalhes operacionais do sistema, as organizações envolvidas e o delineamento do método para avaliar a contribuição do sistema. 
Antes de avançar na descrição do relato técnico, cabe realizar uma harmonização dos conceitos dos três principais componentes da formação continuada em gestão de projetos. $\mathrm{Na}$ Figura 1, encontram-se os níveis, os quais envolvem o programa educacional (PVGP), a vivência gerencial (Jogo de gestão de projetos) e o simulador (PMS-Sim).

Para que o leitor deste relato compreenda melhor a inter-relação entre os componentes, decidiu-se apresentar a definição adotada com referências do campo de estudo (Figura 2). O PVGP, como um programa educacional, trata do processo de aprendizagem e ensino organizado para a formalização de disciplinas, cursos e treinamento em gestão de projetos (Bacich \& Moran, 2018; Carreiro \& Oliveira, 2018). Ele é o componente macro.

O Jogo de gestão de projetos representa uma estratégia de aprendizagem como exercício de tomada de decisões, capaz de reproduzir, de forma simplificada, uma situação que poderia ser real (Sauaia \& Zerrenner, 2009), um ambiente vivencial simulado com suficiente similitude com o mundo real, capaz de induzir respostas que seriam aplicadas à realidade. Caracteriza-se, também, como uma técnica, na qual mudanças de comportamento e no aprendizado podem ocorrer e o comportamento gerencial pode ser observado (Santos \& Oliveira, 2019), componente intermediário (meso), pois alinha os objetivos educacionais do PVGP com as regras econômicas e gerenciais do PMS-Sim.

Já o PMS-Sim representa o simulador educacional, um instrumento didático constituído por um conjunto de regras econômicas a serem praticadas para exercitar teorias, conceitos e técnicas (Sauaia, 2013). Os simuladores na área de negócios são usados para a tomada de decisões, pois diferentes cenários podem ser avaliados sem risco. Eles também são usados na educação gerencial (Borrajo et al., 2010), componente micro.

Figura 1 - Componentes da formação em gestão de projetos



Fonte: Elaborado pelos próprios autores (2020). 
Figura 2 - Níveis e descrição dos componentes da formação em gestão de projetos

\begin{tabular}{|c|c|c|}
\hline Componente & Descrição sumarizada & Nível \\
\hline PVGP & $\begin{array}{l}\text { - Conjunto de ferramentas que visam melhorar o processo de } \\
\text { aprendizagem e ensino. Ações práticas aplicadas no dia a dia em sala } \\
\text { de aula (Bacich \& Moran, 2018); } \\
\text { Conteúdo educacional para formação continuada em gestão de } \\
\text { projetos (Carreiro \& Oliveira, 2018). }\end{array}$ & Macro \\
\hline $\begin{array}{c}\text { Jogo de } \\
\text { Gestão de } \\
\text { Projetos }\end{array}$ & $\begin{array}{l}\text { - Estratégia de aprendizagem como exercício de tomada de decisões } \\
\text { capaz de reproduzir de forma simplificada uma situação que poderia } \\
\text { ser real (Sauaia \& Zerrenner, 2009); } \\
\text { Ambiente vivencial simulado com suficiente similitude com o } \\
\text { mundo real capaz de induzir respostas que seriam aplicadas à } \\
\text { realidade (Santos \& Oliveira, 2019); } \\
\text { Técnica que estimula mudanças de comportamento e no aprendizado, } \\
\text { na qual o comportamento gerencial pode ser observado (Santos \& } \\
\text { Oliveira, 2019). }\end{array}$ & Meso \\
\hline PMS-Sim & $\begin{array}{l}\text { - Instrumento didático constituído por um conjunto de regras } \\
\text { econômicas a serem praticadas para exercitar teorias, conceitos e } \\
\text { técnicas (Sauaia, 2013); } \\
\text { - Simuladores adotados na área de negócios para a tomada de } \\
\text { decisões, pois diferentes cenários podem ser avaliados sem risco; } \\
\text { eles também são usados na educação gerencial (Borrajo et al., 2010); } \\
\text { - Simulador desenvolvido para auxiliar a dinâmica de jogo de } \\
\text { empresas em Gestão de Projetos (Carreiro \& Oliveira, 2018). }\end{array}$ & Mirco \\
\hline
\end{tabular}

Fonte: Elaborado pelos autores (2020).

Tal esclarecimento pode ser útil para a noção quanto ao desenvolvimento de uma aprendizagem gerencial, pois não basta criar um sistema com algoritmos e funções matemáticas, se não há componentes didáticos que auxiliam mediadores e educandos.

\subsection{Caracterização do relato técnico}

O PMS-Sim surgiu a partir da demanda de um simulador e de um jogo de empresas para o desenvolvimento de um treinamento personalizado para uma empresa multinacional automobilística (Carreiro \& Oliveira, 2015). O objetivo da instituição, ao demandar a atividade, era desenvolver competências dos colaboradores para a gestão de projetos por meio de práticas vivenciais.

Sendo assim, em 2012, iniciou-se a elaboração do simulador PMS-Sim para atender as características de projetos de automóveis e os pontos fundamentais para a gestão de projetos. Para isso, foi de fundamental importância compreender o contexto da organização e os aspectos peculiares do setor, bem como fazer um levantamento com os responsáveis.

Após o levantamento das informações pertinentes, criou-se o simulador e o contexto do jogo de empresas. Inicialmente, desenvolveu-se uma aplicação teste com alguns colaboradores, e após elaborou-se um treinamento formal com vinte e um 
colaboradores da organização (Carreiro \& Oliveira, 2015).

A equipe de projetos que participou da aplicação era formada por três gerentes, seis coordenadores, sete especialistas e cinco analistas. Após a realização da atividade vivencial, aplicou-se um questionário com o intuito de realizar um levantamento de opinião e verificou-se que a dinâmica do jogo de empresas e o simulador PMS-Sim possibilita a formação de competências (Carreiro \& Oliveira, 2015).
Desta forma, compreendeu-se que a aplicação em ambientes universitários poderia ser possível, desde que fosse criado um Programa Vivencial em Gestão de Projetos. Assim sendo, desenvolveu-se o programa, por meio das pesquisas de Carreiro (2016) e Carreiro e Oliveira (2018), sendo essencial a criação de um software para o simulador.

Portanto, elaborou-se uma interface com o intuito de facilitar o uso e a personalização da simulação. Na Figura 3, é possível visualizar a tela inicial do PMS-Sim:

Figura 3 - Tela Inicial do PMS-SIM

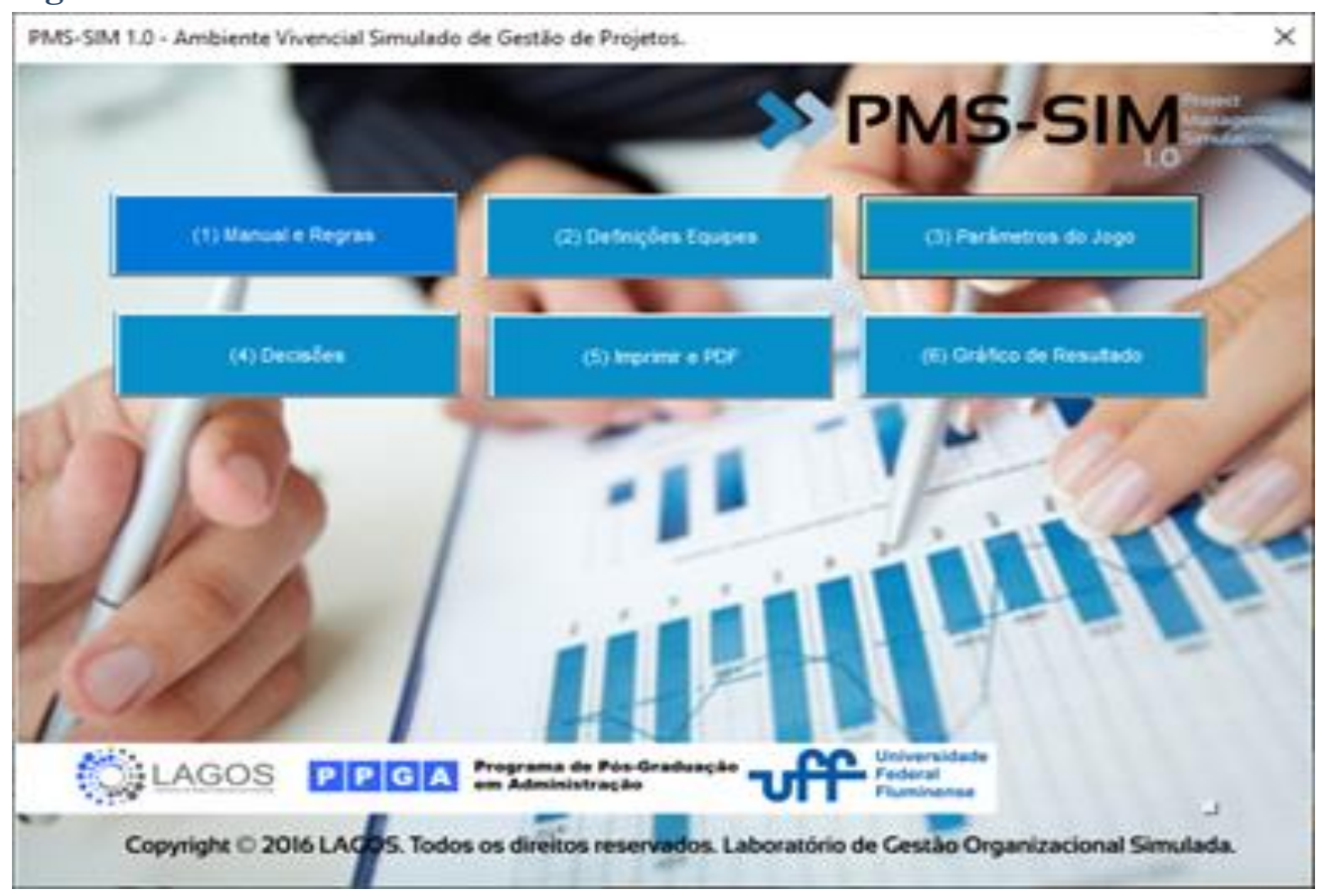

Fonte: Elaborado pelos próprios autores (2020).

Nesta interface, o mediador tem acesso ao manual e regras, definições das equipes, parâmetros do jogo, decisões, impressão e pdf e gráficos de resultado. Ao clicar no botão Definições Equipes, abre-se uma tela que permite criar os nomes de cada uma das equipes formadas e vincular uma pasta específica para cada uma delas, bem como para o mediador. Essa ferramenta facilita o processamento das decisões e assegura que apenas a equipe responsável pelo projeto tenha acesso às decisões e assegura ao instrutor a organização 
dos resultados. Na Figura 4, apresenta-se a aba

"Definições Equipes"

Figura 4 - Tela de Parâmetro e Decisões

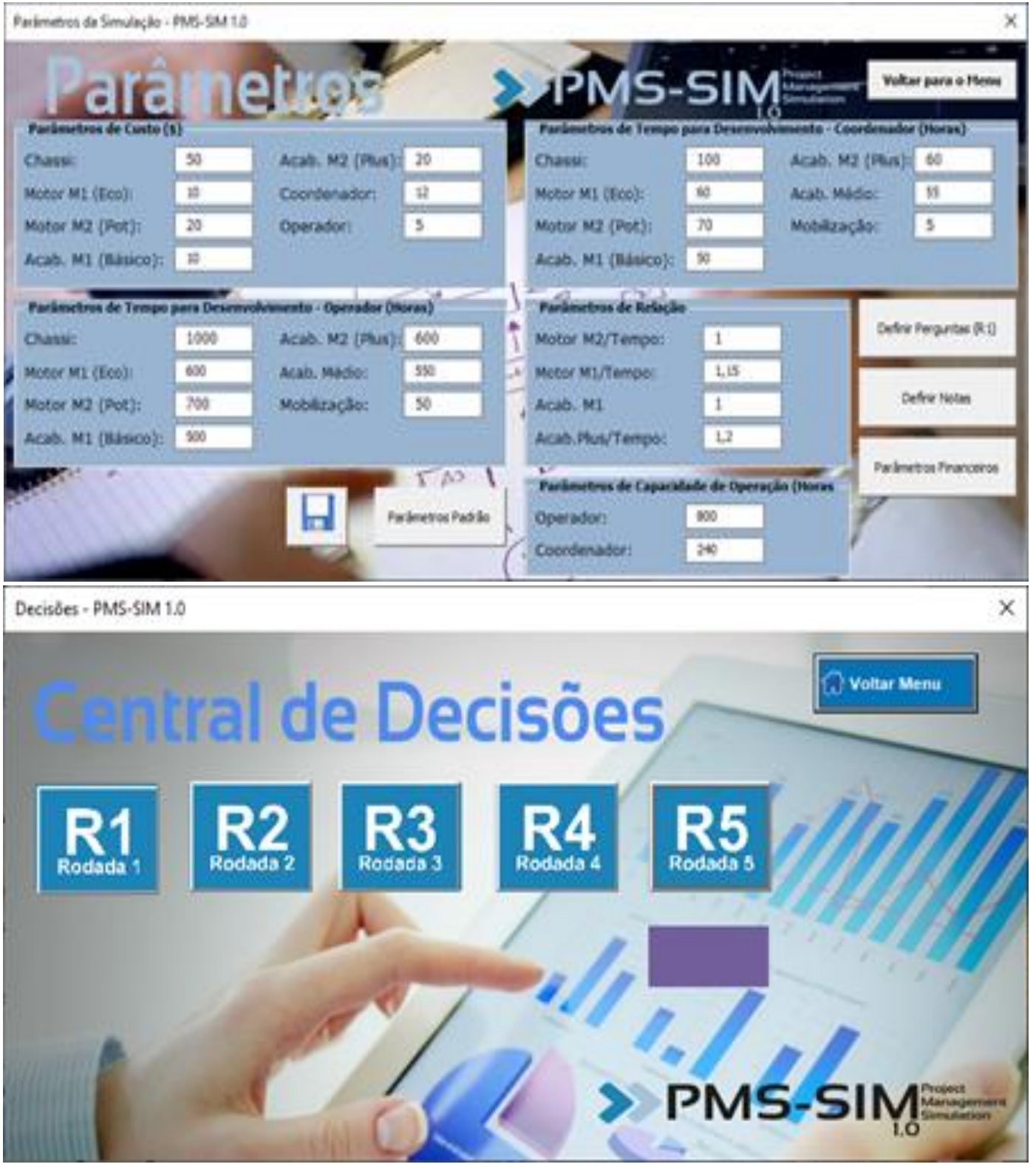

Fonte: Elaborado pelos próprios autores (2020).

O simulador, também, possibilita que o professor modifique os parâmetros do jogo de empresas, para isso ele deve clicar no botão Parâmetros. Dentro deste menu, é possível alterar aspectos de custo, tempo, perguntas, definição de pesos de notas e parâmetros financeiros (Figura 4).

Além das configurações necessárias, o simulador facilita a inserção das decisões tomadas por cada equipe. Deste modo, o instrutor deve acessar o botão Decisões. Como 
se pode ver na Figura 5, é possível acessar as decisões e inserir os dados de cada uma das

Figura 5 - Tela das Rodadas
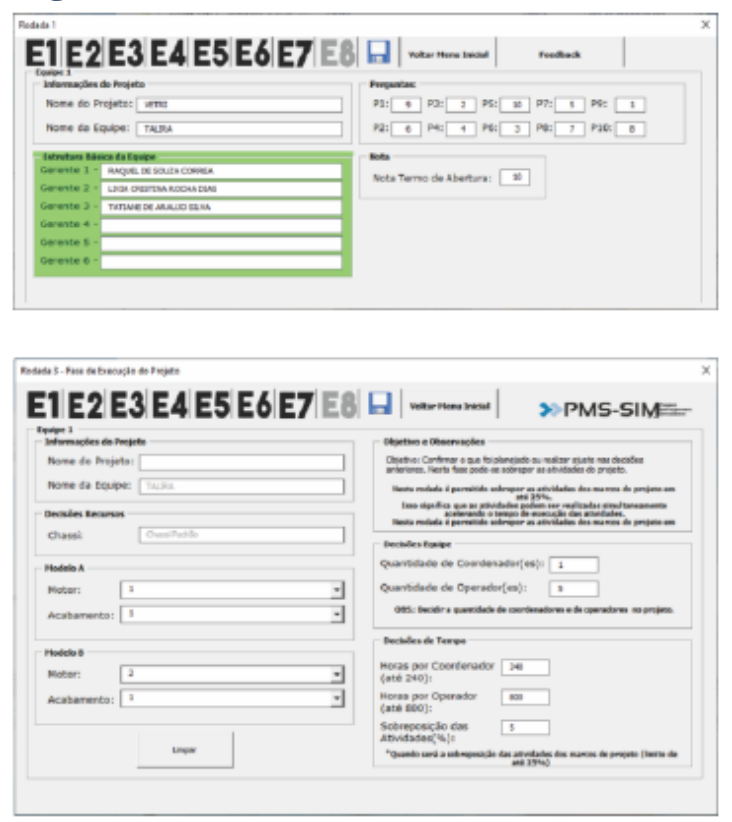

Fonte: Elaborado pelos próprios autores (2020).

O simulador facilita a impressão dos relatórios, os formulários de decisão, a geração dos relatórios e a criação de gráficos. Basta o professor clicar no botão Impressões e PDF. Dentro deste menu, conforme a Figura 6, é cinco rodadas, assim como as telas de cada uma delas.
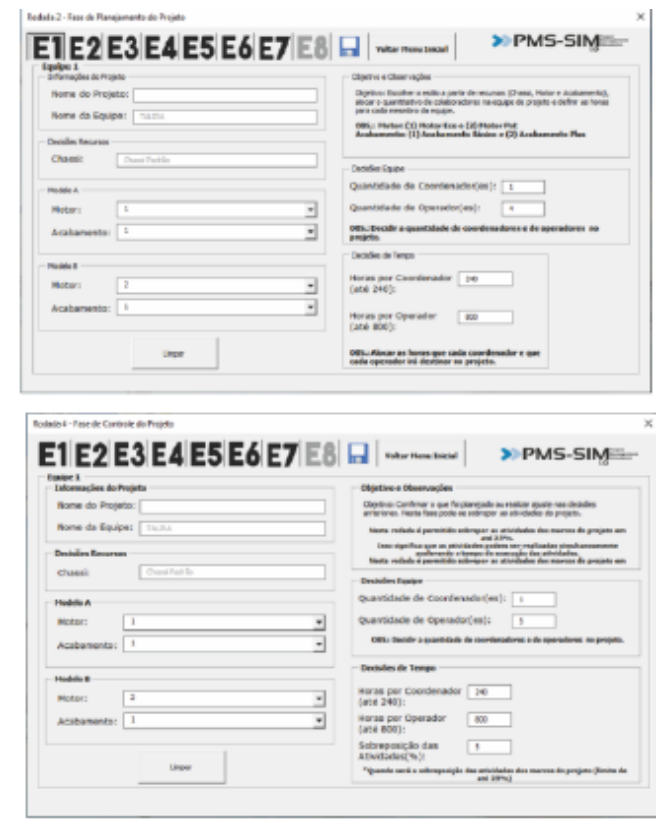

possível selecionar formulários específicos de cada rodada, a quantidade de cópias, escolher os resultados de cada rodada para a criação de PDF e gráfico de resultado e relatórios para o professor. 
Figura 6 - Impressão e Geração de Relatórios e PDF

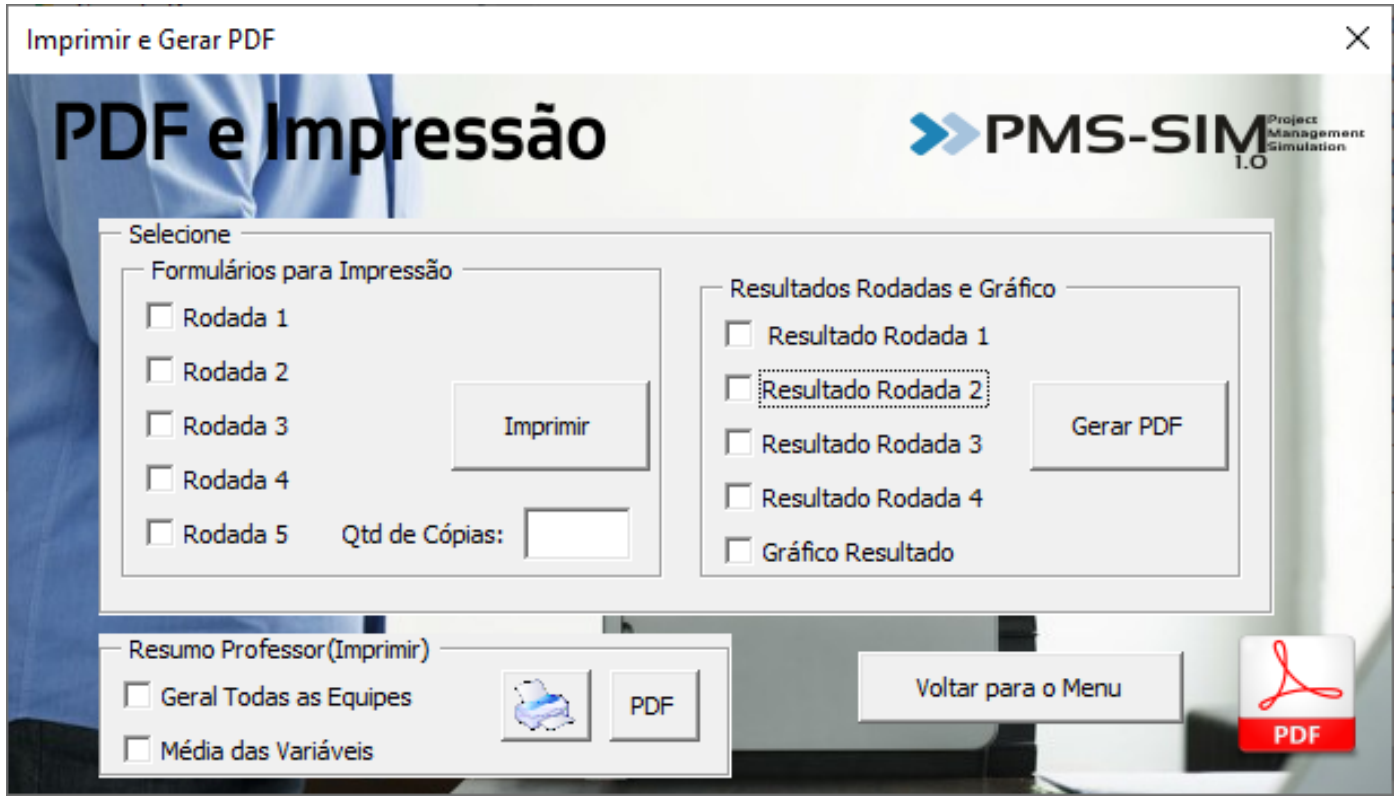

Fonte: Elaborado pelos próprios autores (2020).

Além da aplicação em uma empresa multinacional e em uma universidade federal, efetivou-se, também, a simulação em uma instituição pública federal no ano de 2018. Vale ressaltar que se desenvolveu uma segunda versão do simulador, no ano 2019, na pesquisa de Souza (2019). Nessa pesquisa é apresentada a adaptação do jogo de empresas e do simulador para o uso em incubadoras tecnológicas.

\subsection{Design multimétodo para a avaliação do PMS-Sim}

O simulador educacional (PMS-Sim), assim como as atividades complementares do PVGP, passaram por um processo longitudinal de análise em ambientes e níveis acadêmicoprofissionais distintos. Deste modo, a abordagem orientadora para o desenvolvimento analítico da solução ocorreu em três estágios e também a triangulação multimétodo para atendimento dos objetivos de cada estágio, conforme apresentado na Figura 7. 
Figura 7 - Estágios da pesquisa de avaliação do PMS-Sim

\begin{tabular}{|c|l|c|}
\hline Estágio & \multicolumn{1}{|c|}{ Descrição } & Fonte \\
\hline Estágio 1 & $\begin{array}{l}\text { Desenvolvimento de uma pesquisa com 21 profissionais de uma multinacional } \\
\text { automobilística. Para isso, realizou-se um levantamento de opinião por meio de } \\
\text { questionário e usou-se a comparação das diferenças de opiniões entre os perfis } \\
\text { profissionais (nível hierárquico), bem como foram feitas inferências utilizando } \\
\text { uma análise univariada t de student com a finalidade de verificar as médias das } \\
\text { respostas. }\end{array}$ & $\begin{array}{c}\text { Carreiro \& } \\
\text { Oliveira (2015) }\end{array}$ \\
\hline Estágio 2 & $\begin{array}{l}\text { Adaptação para acadêmicos do curso de Administração em turmas de graduação, } \\
\text { somando 60 estudantes, com o objetivo de analisar a evolução do conhecimento } \\
\text { em gestão de projetos, adotando-se o modelo lógico de Kriz e Hense (2006). }\end{array}$ & $\begin{array}{c}\text { Carreiro \& } \\
\text { Oliveira (2018), } \\
\text { Souza (2019) }\end{array}$ \\
\hline Estágio 3 & $\begin{array}{l}\text { Estágio de ampliação para ambientes de inovação, com o objetivo de analisar as } \\
\text { contribuições e limitações da aplicação do PVGP para Incubadoras de Empresas. } \\
\text { participante e o levantamento por meio de entrevistas e análise de conteúdo. A } \\
\text { partir do caso de duas incubadoras, a aplicação ocorreu em uma incubadora da } \\
\text { região Sul Fluminense. O modelo lógico de Kriz e Hense (2006) norteou a } \\
\text { construção do programa. }\end{array}$ & \begin{tabular}{c} 
Souza (2019) \\
\hline
\end{tabular} \\
\hline
\end{tabular}

Fonte: Elaborado pelos próprios autores (2020).

No processo de avaliação do PMS-Sim, adotou-se uma combinação de métodos quanti e qualitativos em estudo de caso longitudinal com profissionais de gestão de projetos, estudantes e docentes, em contexto de formação continuada, em três momentos distintos, com intervalos bianuais, o que levou seis anos, desde a concepção do piloto do simulador (2013) até o estágio atual (2019). Neste sentido, considerouse multimétodo como a triangulação (Denzin \& Lincoln, 2006) de instrumentos que possibilitam a combinação de estudos que permitem a diversificação de informações, no caso deste estudo, survey, resultados de provas e entrevistas em grupo focal e em profundidade.

A abordagem orientadora para o desenvolvimento analítico do PMS-Sim, usando o multimétodo nos estágios longitudinais, possibilitou avançar na compreensão da contribuição do artefato que dinamiza a formação continuada no PGVP em contextualização provocada por mudanças na gestão prática de um projeto. Nesse processo, as atividades no cotidiano do trabalho e de formação continuada são vivenciais e transformadas em um ambiente integrado e dinâmico.

$\mathrm{Na}$ análise dos três estágios em que houve a atualização do PMS-Sim, o jogo de gestão de projetos foi crucial para a condução do PGVP e assim regulou e potencializou a qualificação dos participantes. Na Figura 8, apresenta-se a evolução do desenvolvimento e a avaliação do PMS-Sim. 
Figura 8 - Fluxo do desenvolvimento e avaliação do PMS-Sim

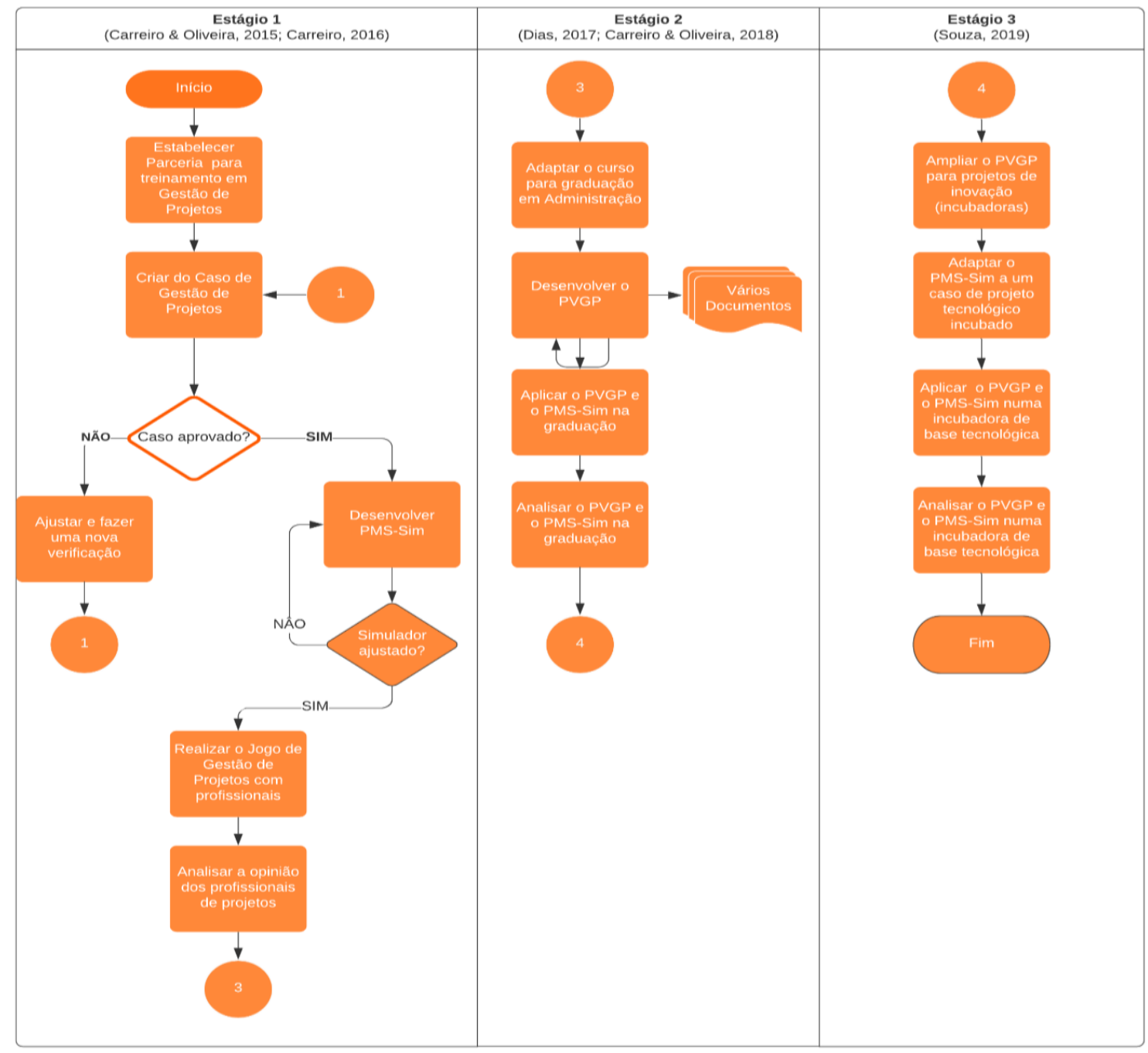

Fonte: Elaborado pelos próprios autores (2020).

No estágio 1 , houve a concepção do artefato com a construção do caso voltado para o treinamento de profissionais da área de gestão de projetos de uma empresa multinacional automobilística. Para análise, utilizou-se o levantamento da opinião dos participantes e posterior comparação de médias respostas dos diferentes especialistas em gestão de projetos (Carreiro \& Oliveira, 2015; Carreiro, 2016).

No estágio 2, o projeto foi adaptado para o ambiente acadêmico, aplicando-se o PVGP num curso de graduação em administração (Carreiro \& Oliveira, 2018), para tanto o programa realizou-se com turmas de graduação, totalizando sessenta estudantes, cujo objetivo foi analisar a evolução do conhecimento em gestão de projetos, adotando o modelo lógico de Kriz e Hense (2006) que traz um inventário de análise e de avaliação de programas educacionais que usam o jogo de empresas como recurso de aprendizagem. Neste estudo, o desempenho individual dos participantes foi avaliado pela comparação da variação das notas em cada fase do programa. 
Além disso, houve a análise da opinião dos participantes do grupo de foco pela análise de conteúdo (Dias, 2017). Ainda, neste estágio, ocorreu o refino dos conteúdos que estavam associados ao PMS-Sim e ao PVGP a partir das entrevistas com docentes que participaram da condução do programa vivencial, bem como docentes com experiência em gestão de projetos. Nesta etapa, utilizou-se a técnica Multicritério com especialistas da AHP (Analytic Hierarchy Process), como parte do estudo de Souza (2019), que se consolidou no estágio 3.

Já no estágio 3, houve a ampliação do programa vivencial com uma nova versão do PMS-Sim voltado para ambientes de inovação, com o objetivo de analisar as contribuições e as limitações da aplicação do PVGP para Incubadoras de Empresas. $\mathrm{O}$ estudo (de natureza qualitativa e exploratória) utilizou como técnicas a pesquisa participante e o levantamento por meio de entrevistas e análise de conteúdo. Tal estudo ocorreu a partir do caso de duas incubadoras, com aplicação em uma incubadora da região Sul Fluminense (Souza, 2019).

\subsection{Procedimentos técnicos para análise da solução}

$\mathrm{Na}$ descrição dos procedimentos técnicos, apresentam-se os três estágios que compõem a triangulação multimétodo do relato e são estes que formam a trajetória de análise dos PMS-Sim.
3.3.1 Levantamento de opinião com análise quantitativa (Estágio 1)

No estágio 1, o estudo teve como objetivo analisar a opinião de profissionais quanto às potencialidades de um jogo de empresas dinamizado pelo PMS-Sim. A pesquisa de cunho descritivo foi realizada por meio de um levantamento de opinião com 21 profissionais da área de projetos de uma multinacional do setor automobilístico.

O instrumento de coleta de dados foi baseado nos estudos de Carvalho e Rabechini Jr (2006) que analisaram as competências relevantes em gestão de projetos sob três aspectos: o gestor, a equipe e o contexto da organização para o desenvolvimento de projetos.

No que se refere à abordagem do tratamento dos dados, o estudo utilizou a quantitativa. As opiniões dos profissionais revelaram a existência de distintas impressões quanto às contribuições da atividade vivencial na formação de competências. Adotou-se, para análise das médias das opiniões dos participantes, o teste $t$ de student que objetiva a comparação das médias de amostras. Esse teste demonstrou que as médias das opiniões dos participantes foram diferentes.

\subsubsection{Procedimentos mistos na adaptação acadêmica (Estágio 2)}

No estágio 2, o aspecto quantitativo está consignado pela análise das notas obtidas na prova P1 e nas provas de certificações simuladas CAPM e PMP, desenvolvida por 
Carreiro (2016), e usada para conceder a certificação para desempenhos superiores a $70 \%$ (setenta por cento) de acertos. Também foram utilizadas as notas com escala intervalar para tratamentos (Figura 9).

Figura 9 - Síntese dos procedimentos para coleta e tratamento dos dados quantitativos

\begin{tabular}{|c|c|c|c|l|}
\hline $\begin{array}{c}\text { Tipo de } \\
\text { Pesquisa }\end{array}$ & $\begin{array}{c}\text { Tipo de } \\
\text { dados }\end{array}$ & \multicolumn{1}{|c|}{ Variáveis Utilizadas } & \multicolumn{2}{|c|}{ Técnicas de Análise } \\
\hline $\begin{array}{c}\text { Descritiva por } \\
\text { Levantamento }\end{array}$ & $\begin{array}{l}\text { Quantitativo } \\
\text { intervalares }\end{array}$ & $\begin{array}{l}\text { Teste de Conhecimentos Básicos de projetos } \\
\text { (P1); Teste CAPM; Teste PMP e Notas no Jogo } \\
\text { de Gestão de Projetos. }\end{array}$ & Univariada & $\begin{array}{l}\text { Média ponderada } \\
\text { Variação } \\
\text { Percentual }\end{array}$ \\
\cline { 3 - 5 } & $\begin{array}{l}\text { Teste de Conhecimentos Básicos de projetos } \\
\text { (P1); Teste CAPM; Teste PMP. }\end{array}$ & Bivariada & $\begin{array}{l}\text { Teste não } \\
\text { paramétrico U de } \\
\text { Mann-Whitney }\end{array}$ \\
\hline
\end{tabular}

Fonte: Dias (2017).

O programa vivencial aplicado a duas turmas contou com sessenta (sessenta) participantes, sendo que se buscou ouvir o maior número de participantes possível por meio de uma amostra por acessibilidade. Para isso, utilizou-se o grupo de foco. Nesta abordagem, além de termos a possibilidade de 'entrevistar' mais pessoas, o resultado da coleta de dados propicia informações resultantes da interação da abordagem grupal. Após isso, foram feitas as transcrições das gravações das referidas dinâmicas e seguiu-se a análise de conteúdo para a identificação dos fatores de análise. Observe-se que o grupo focal, além de ser a técnica de coleta, também comportou algum grau de análise qualitativa, pois se trata da construção coletiva de significados.

O processo de adaptação do PMS-SIM para empresas de tecnologia e incubadoras ocorreu a partir da análise AHP e das entrevistas semiestruturadas com os gerentes de duas incubadoras, escolhidas por conveniência. A primeira incubadora está associada à Universidade do Estado do Rio de Janeiro UERJ e localiza-se na região Sul-Fluminense. A segunda incubadora está associada à Universidade Federal de Juiz de Fora - UFJF e localiza-se na Zona da Mata Mineira.

A técnica AHP foi utilizada para hierarquizar os fatores relativos às áreas de conhecimento em gestão de projetos, dado o seu grau de importância para o processo de incubação. Seguindo o modelo Pró-Valor de Carvalho e Rabechini Jr. (2017), as áreas de conhecimento foram agrupadas em dois subgrupos.

O primeiro subgrupo aglutinou as áreas de conhecimento em gestão de projetos que estão associadas diretamente ao triângulo das restrições, sendo elas: gerenciamento do prazo, gerenciamento do escopo, gerenciamento dos custos e gerenciamento da qualidade. $\mathrm{O}$ 
segundo subgrupo aglutinou as áreas de conhecimento que não estão associadas diretamente ao triângulo das restrições, sendo elas: gerenciamento das comunicações, gerenciamento dos recursos, das aquisições e gerenciamento do risco. Como no modelo PróValor o gerenciamento da integração e dos stakeholders permeiam todo o modelo, eles não foram hierarquizados em razão da sua importância implícita para a gestão de projetos (Hornstein, 2015; Carvalho \& Rabechini Jr., 2017).

Em razão do grau de importância atribuído pelos gerentes, os resultados da análise AHP indicaram que, dentre as áreas de conhecimento em gestão de projetos atreladas ao processo de incubação, o programa deveria evidenciar o gerenciamento do prazo $(0,465)$ e o gerenciamento dos riscos $(0,318)$.

3.3.3 Levantamento de opinião e pesquisa qualitativa com participantes de incubadoras de empresas (Estágio 3)

No estágio 3, desenvolveu-se a entrevista semiestruturada com os gerentes das incubadoras, cujo roteiro foi adaptado dos estudos de Cruz (2017), com um total de 31 questões. Esse modelo foi escolhido, pois tem objetivo de investigar as associações entre o processo de incubação e o gerenciamento de projetos. Para o processo de avaliação da adaptação do roteiro, foram consultados dois pesquisadores no processo de incubação, ambos com nível de doutorado. Vale ressaltar que se aceitaram todas as sugestões de melhoria do instrumento. Além disso, todas as entrevistas foram gravadas, transcritas e analisadas por intermédio da técnica de análise de conteúdo. Para tanto, a análise categorial teve como base as áreas de conhecimento propostas pelo PMI (Bardin, 2016; PMI, 2017).

Conforme demonstra a Figura 10, em algum momento das entrevistas, todas as áreas de conhecimento foram evidenciadas quanto à associação ao processo de incubação. Como enfatiza o modelo Pró-Valor (Carvalho \& Rabechini Jr., 2017), nota-se o gerenciamento da integração e dos stakeholders com maior volume de excertos, em razão das características fundamentais dessas áreas para o gerenciamento de projetos e para o processo de incubação (Guillen \& Veras, 2018). Em menor volume de citação está o gerenciamento das aquisições, uma vez que a incubadora pouco se envolve no processo de aquisição operacionalizado pela empresa incubada. 
Figura 10 - Áreas de conhecimento em gestão de projetos atreladas ao processo de incubação

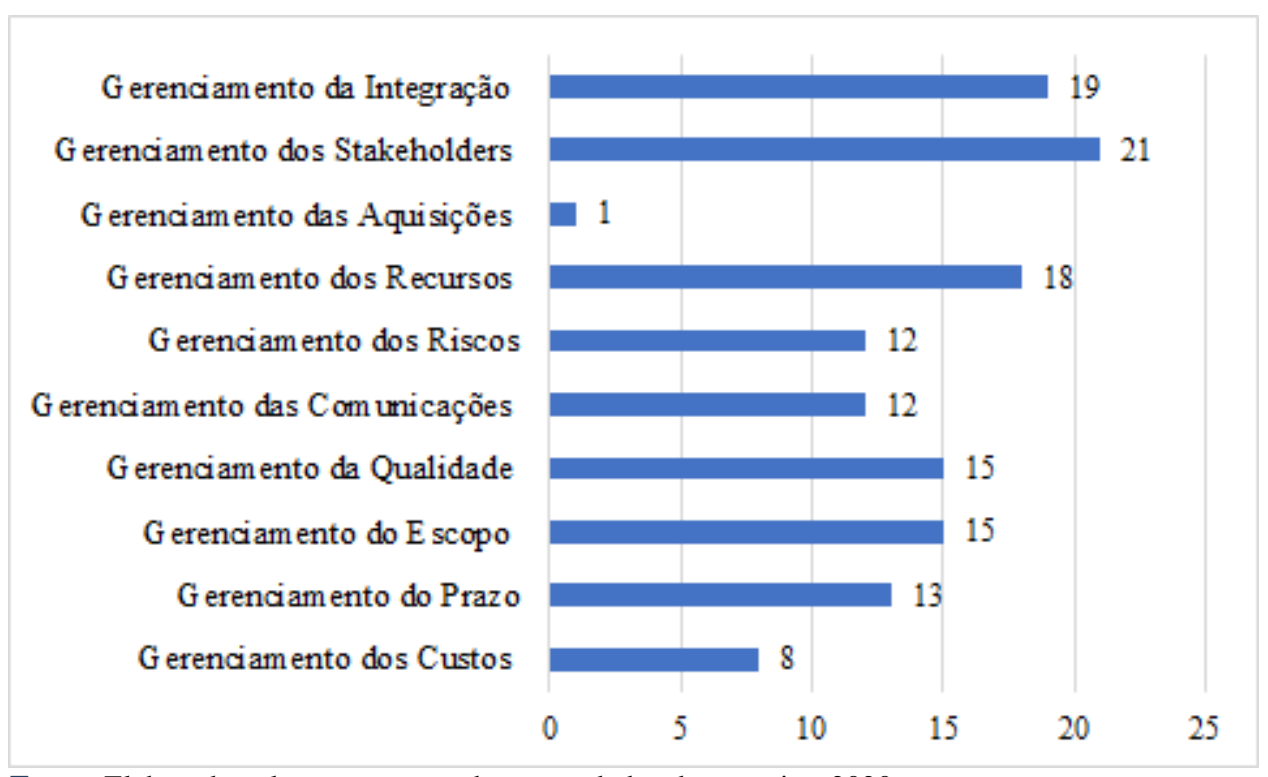

Fonte: Elaborado pelos autores com base nos dados da pesquisa, 2020.

Com base nesses dados, a adaptação do programa para o novo contexto contemplou as áreas evidenciadas no modelo AHP, bem como os apontamentos dos gerentes das incubadoras durante as entrevistas. Após a adaptação, foi realizado o teste piloto junto ao Centro Federal de Educação Tecnológica, Celso Suckow, campus Valença, Rio de Janeiro, na disciplina de Gestão de Projetos, do curso de Administração. Ao todo, participaram da vivência vinte e dois estudantes, que, ao final das experiências, apontaram pontos de melhoria, que foram acatados. Em seguida, o programa adaptado foi aplicado na Incubadora Sul-Fluminense, envolvendo dez estudantes dos cursos de engenharias da Faculdade de Tecnologia da UERJ - Campus Resende. Esses estudantes foram escolhidos por manterem alguma relação com a incubadora.

Após a vivência, os estudantes foram submetidos a entrevistas semiestruturadas. O roteiro de entrevistas, com vinte e três questões, foi adaptado a partir dos estudos de Dias (2017) que avalia a qualidade de um jogo de empresas em gestão de projetos. A adaptação foi avaliada por três especialistas em jogos de empresas em nível de mestrado e doutorado. As entrevistas foram gravadas e transcritas na íntegra. Os dados foram analisados por análise de conteúdo, seguindo os parâmetros do modelo lógico de Kriz e Hense (2006).

\section{Contexto do Projeto ou Situação-Problema \\ O contexto do projeto de} desenvolvimento do PMS-Sim é descrito nesta seção que compreende a organização patrocinadora da proposta, o dilema teóricoempírico que intensificou a solução tecnológica e os mecanismos desenvolvidos para sua concepção, execução e análise. 


\subsection{Caracterização da organização}

O PMS-Sim foi um projeto concebido pelo grupo de pesquisa Laboratório de Gestão Organizacional Simulada (LAGOS) da Universidade Federal Fluminense (UFF), do campus de Volta Redonda, no estado do Rio de Janeiro (LAGOS, 2020). A UFF é uma instituição pública de ensino superior, com sede em Niterói, criada em 1960. É considerado um dos principais centros de excelência no Brasil e conta com 42 unidades de Ensino, com 125 cursos de graduação presenciais e seis cursos de graduação a distância. Na Pós-Graduação Stricto Sensu, são 85 programas de PósGraduação e 126 cursos, sendo 44 de doutorado, 66 de mestrado acadêmico e dezesseis mestrados profissionais. A PósGraduação Lato Sensu apresenta 150 cursos de especialização (UFF, 2020).

Em 2009, houve a vinculação do programa ao grupo de pesquisa também denominado LAGOS e assim começaram os primeiros projetos de iniciação científica. Ao longo dos anos, ocorreram avaliações periódicas dos resultados do programa. A partir de 2013, iniciaram-se as ações de Stricto Sensu com a vinculação de disciplina junto ao mestrado profissional em Administração, no qual foi possível iniciar parcerias com treinamento junto a empresas instaladas na região de atuação do mestrado, com destaque para a Peugeot Citroen (PSA) e MAN Latin América. Também, neste período, começaram a ser desenvolvidos estudos empíricos com os alunos do mestrado, utilizando os fundamentos dos jogos de empresas como ambiente de pesquisa.

O desenvolvimento do simulador educacional PMS-Sim foi concebido inicialmente por Oliveira e Teodoro (2013), mas sua nova versão recebeu aprimoramentos com um sistema de apoio ao lançamento das decisões, adequações para o uso instrutor e recursos didáticos (manuais, exercícios de fixação aos moldes de certificação em gestão de projetos), bem como o planejamento educacional para a sua execução (Carreiro \& Oliveira, 2018).

\subsection{Caracterização do projeto/problema analisado}

No contexto da formação continuada em gestão de projetos, existem esforços para integrar a teoria e a prática em algumas instituições acadêmicas, como descreve Patah et al. (2016), entretanto há lacunas quanto à dinamização de todos as fases de um projeto além do planejamento, e os jogos de empresas, mediados pelos simuladores organizacionais, podem proporcionar a vivência de todas as fases próximas da realidade. (Carreiro \& Oliveira, 2018). Assim, o PMS-Sim, como o recurso tecnológico na forma de um simulador educacional, justificava-se para promover o dinamismo nas rodadas de jogo com técnica de aprendizagem gerencial.

A própria área de gestão de projetos, como uma disciplina prática e aplicada, necessita de abordagens vivenciais que complementem o ensino convencional, posto 
que, por vezes, os métodos convencionais, centrados no professor, são os únicos empregados em sala de aula. (Bočková et al., 2015; Ojiako et al., 2011). Isso pode criar dificuldades no processo educacional e exigências da vivência dos conceitos (Schmitz et al., 2015). Neste sentido, o problema central que mobilizou o desenvolvimento do PMS-Sim foi:

Como criar mecanismos para a formação em gestão de projetos que ampliam as estratégias de ensino que circunscrevem ou priorizam o planejamento e não as etapas mais dinâmicas de um projeto?

Somada à inquietação do projeto do PMS-Sim, também houve a oportunidade de realizar um programa de treinamento customizado em gestão de projetos para uma empresa multinacional do setor automobilístico, do qual foram derivados os parâmetros lógicos e o caso empresarial para a construção do simulador educacional descrito em detalhes por Carreiro e Oliveira (2015). Desta forma, a responsabilidade pela interlocução do relato técnico envolve também os principais responsáveis pelo projeto descrito por Carreiro e Oliveira $(2015,2018)$.

As organizações envolvidas no projeto foram: (1) a UFF, devido ao vínculo do grupo de pesquisa LAGOS, na qual também ocorreu a aplicação de estudos (Dias, 2017); (2) a multinacional automobilística, que foi a primeira a ter contato com o simulador educacional (Carreiro \& Oliveira, 2015); e (3) duas incubadoras de empresas que participaram dos avanços mais recentes do PMS-Sim (Souza, 2019).

O tema central que envolve o projeto do PMS-Sim apresenta um enquadramento empresarial com interseção educacional, assim voltado para estratégias de aprendizagem gerencial e educação corporativa. Seus principais parâmetros técnicos e educacionais que permitiram sua avaliação baseiam-se no modelo lógico para avaliação de atividades com jogos de empresas proposto por Kriz e Henese (2006), este descrito em detalhes nas aplicações para teste do simulador (Carreiro \& Oliveira, 2015), no estudo de Dias (2017) que trata da avaliação educacional do PVGP e, por conseguinte, o PMS-Sim e na sua adaptação para ambientes de inovação com estudo de Souza (2019).

\section{Tipo de Intervenção e Mecanismos Adotados}

O jogo de Gestão de Projetos dinamizado pelo PMS-Sim possui duas versões. A primeira desenvolvida e aprimorada por Carreiro e Oliveira (2015), Carreiro (2016) e Carreiro e Oliveira (2018). Nesta versão, desenvolveu-se um jogo de empresas com um caso de uma indústria automobilística. Já na segunda versão, aprimorada por Souza (2019), criou-se um caso para incubadoras tecnológicas.

$$
\text { A primeira versão do PMS-SIM é }
$$
composta por cinco rodadas, sendo cada rodada uma fase do ciclo de vida de um projeto (Figura 11). 
Figura 11 - Rodadas da Primeira Versão Jogo de Empresas PMS-SIM

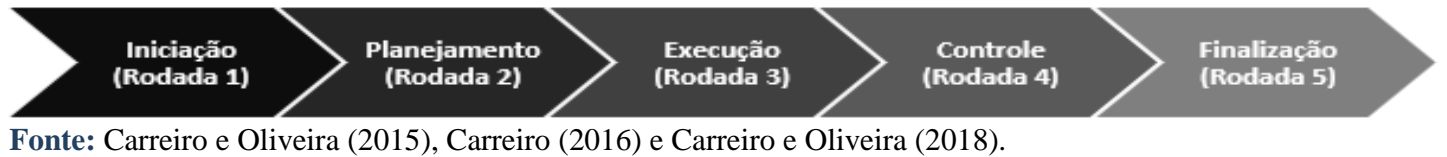

Antes de iniciar o jogo de empresas, o Por meio deste, os alunos conseguem conhecer professor apresenta o caso empresarial e e estudar o caso em questão.

disponibiliza um manual de regras (Figura 12).

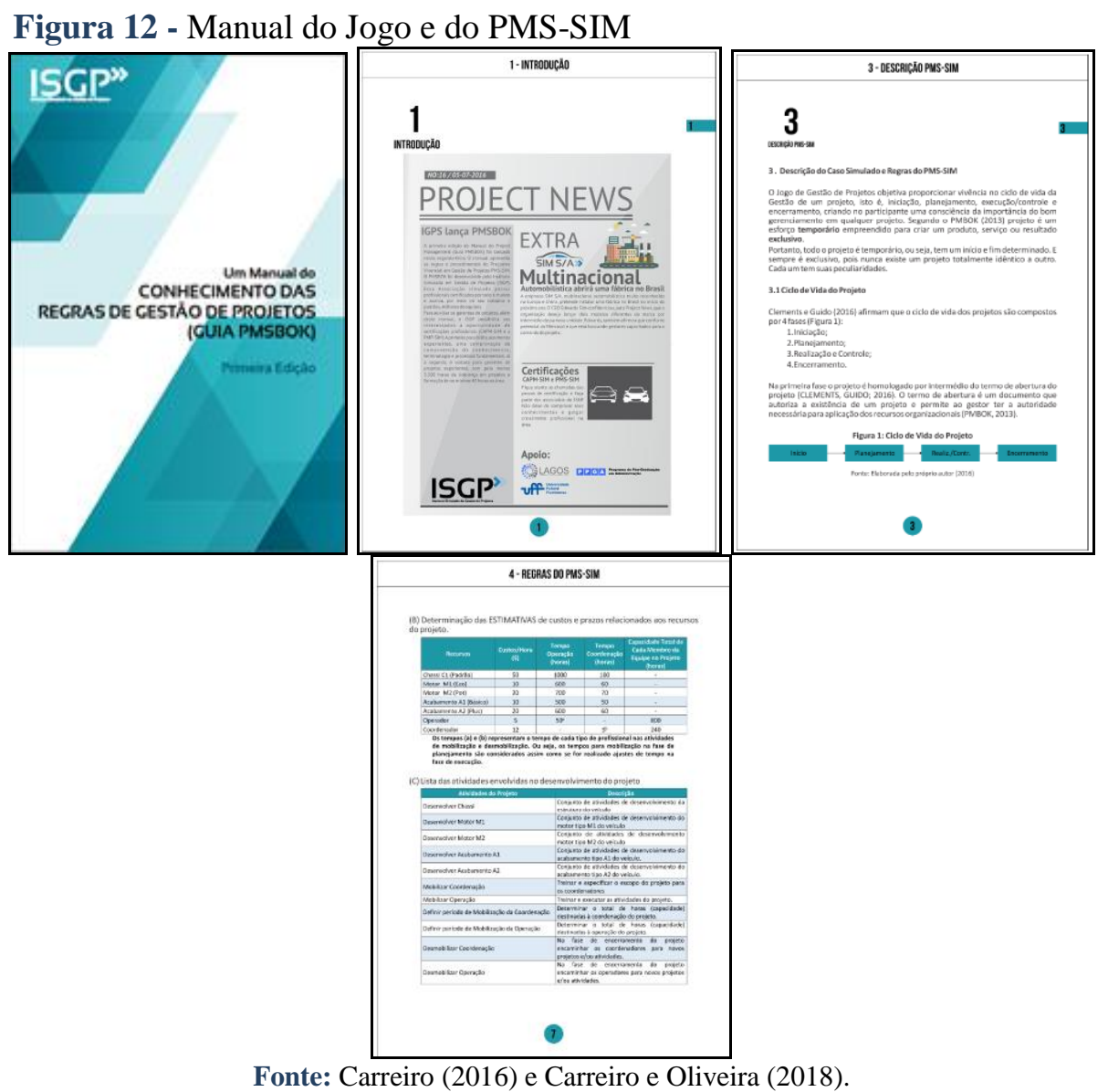

O jogo dinamizado pelo PMS-Sim retrata um caso simulado de uma indústria automobilística que deseja criar uma fábrica que produza dois modelos de automóveis diferentes. Sendo assim, os participantes devem optar pelo tempo de 3.500 horas e o orçamento de $\$ 150.000,00$ para o desenvolvimento do projeto. Dentre as composições de carros possíveis, haverá duas possibilidades de motorização (Motor Econômico e Potente) e duas alternativas de acabamento (Acabamento Básico e Acabamento Plus), sendo o Chassi Padrão para ambos os modelos. Desse modo, são possíveis quatro combinação de modelos diferentes (Carreiro, 2016; Carreiro \& Oliveira, 2018). 
Vale ressaltar que cada modelo de automóvel possui uma rentabilidade e que esta será disputada por todas as equipes, ou seja, se uma equipe escolher a mesma modelagem da outra terá o percentual dividido. Esta rentabilidade pode ser definida pelo professor ou podem ser utilizados os parâmetros do padrão (Tabela 1).

Tabela 1 - Rentabilidade dos modelos

\begin{tabular}{ccccc}
\hline & $\begin{array}{c}\text { Motor Eco + } \\
\text { Acabamento } \\
\text { Básico }\end{array}$ & $\begin{array}{c}\text { Motor Eco + } \\
\text { Acabamento } \\
\text { Plus }\end{array}$ & $\begin{array}{c}\text { Motor Pot. + } \\
\text { Acabamento } \\
\text { Básico }\end{array}$ & $\begin{array}{c}\text { Motor Pot. + } \\
\text { Acabamento } \\
\text { Plus }\end{array}$ \\
\hline Rentabilidade & $10 \%$ & $15 \%$ & $20 \%$ & $25 \%$ \\
\hline
\end{tabular}

Fonte: Elaborado pelos autores (2020).

Cada membro da equipe também interpretará um perfil diferente de stakeholders. Para isso, foram criados cartões e há um sorteio a cada rodada para saber qual é o papel que cada um deverá interpretar (Figura 9). Há quatro perfis: (1) Líder; (2) Solidário; (3) Resistente; e (4) Desatento. Neste cartão, há um score de características apresentadas por níveis de estrelas e, no verso do cartão, explica-se o perfil e as atitudes do personagem (Figura 13). O objetivo da criação de perfis é fazer com que os alunos compreendam, na prática, os principais tipos de características dos stakeholders existentes em um projeto e saibam lidar com essas diferenças.

Figura 13 - Perfis dos gerentes de projetos
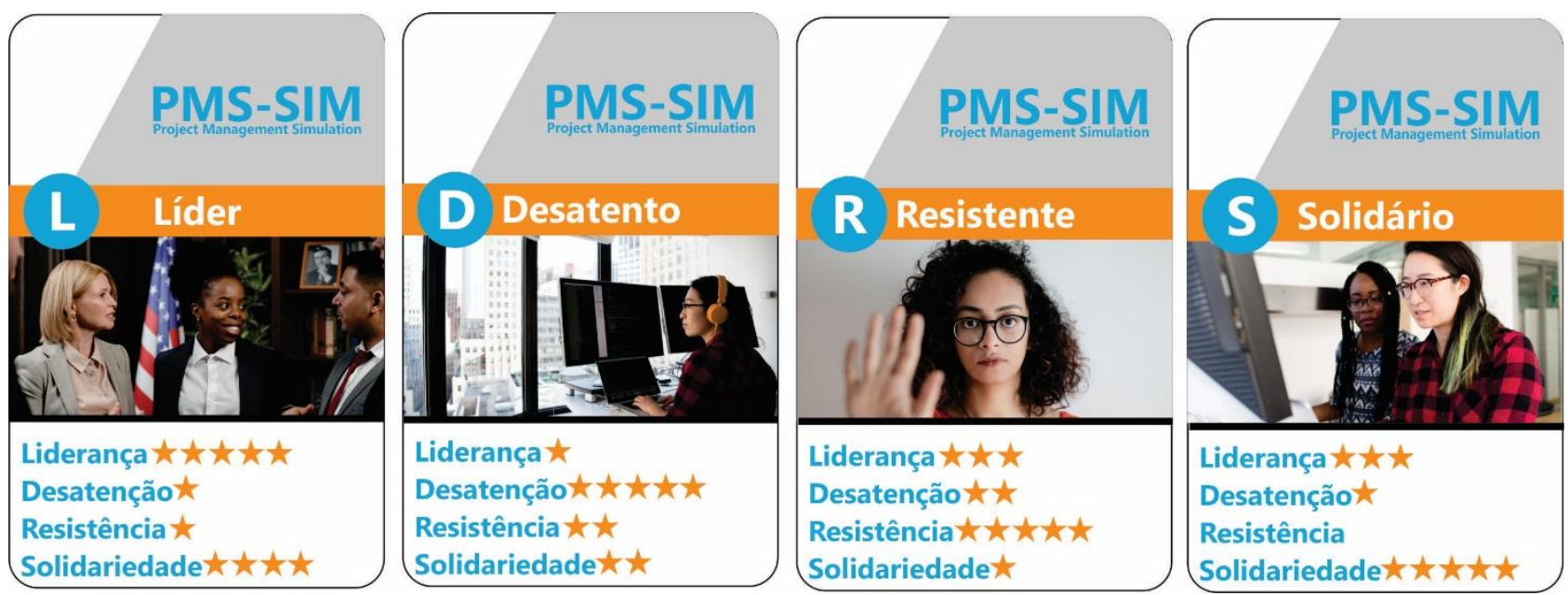

Nota. Adaptado de Morillo, C., 2018a. Pessoa Pensando. [image], Pexels (https://www.pexels.com/pt-br/foto/adultoambiente-de-trabalho-area-de-trabalho-atividade-1181676/). CC BY 2.0; Morillo, C., 2018b. Pessoa Ajudando no Ambiente de trabalho [image] Pexels (https://www.pexels.com/pt-br/foto/adulto-ajudar-ambiente-de-trabalho-apoio-1181472/). CC BY 2.0; Piacquadio, A., 2020. Pessoa Dizendo Não. [image] Pexels (https://www.pexels.com/pt-br/foto/mulher-de-pe-retratooculos-3762802/). CC BY 2.0; Richelieu, A., 2020. Liderança. [image] Pexels (https://www.pexels.com/pt-br/foto/bandeiranorte-americana-bandeira-dos-estados-unidos-afro-americano-mulher-afro-americana-4427626/). CC BY 2.0.

Fonte: Elaborado pelos próprios autores baseado em Morillo (2018a), Morillo (2018b), Piacquadio (2020) e Richelieu (2020). 
Desta forma, ao se iniciar a primeira rodada (iniciação), os participantes recebem um formulário de decisões no qual deverão criar o termo de abertura do projeto (Figura 10). Dentre as decisões tomadas, eles definirão: (1) Nome do projeto e da equipe; (2) Data; (3) Objetivo Geral do Projeto; (4) Benefícios Esperados; (5) Prazo e Custo; (6) Escopo do Projeto; Estrutura Básica da Equipe; e (7) Hierarquização dos Riscos do Projeto.

Após a finalização da rodada, o professor corrige as decisões e a hierarquização dos riscos e apresenta um retorno para os acertos e os erros. As equipes que conseguirem uma nota acima de oito, nesta fase, obterão a autorização para começar a fase de planejamento, porém aquelas que não conseguirem a nota mínima deverão refazer o termo de abertura. Após a autorização do projeto, as equipes podem iniciar a rodada dois, planejamento. Nesta rodada, os gestores do projeto simulado escolhem o acabamento e a motorização dos dois modelos e contratam coordenadores e técnicos de projetos (recursos) que auxiliarão no planejamento e na execução do projeto.

Figura 14 - Formulários de Rodadas

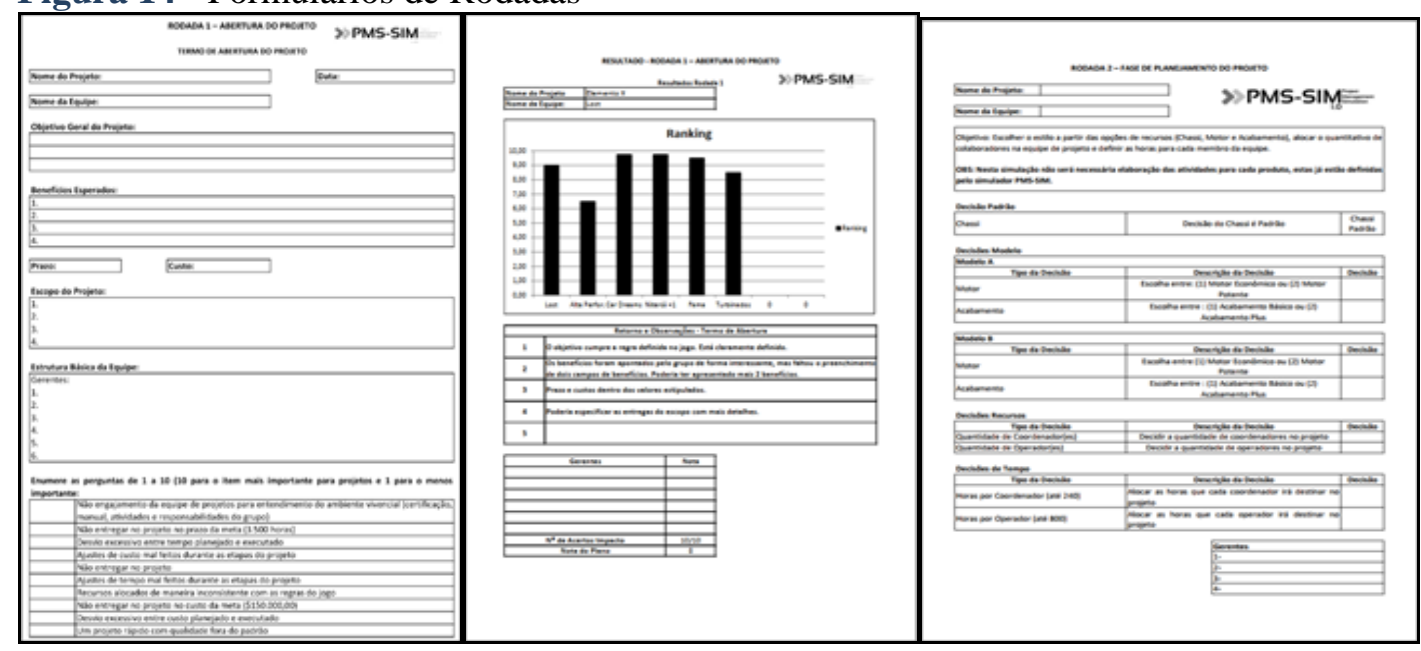

Fonte: Carreiro (2016).

Após a entrega das decisões da rodada 2, o professor insere os dados no simulador e este gera um relatório de planejamento de tempo, custo para as equipes, escopo, rentabilidade e capacidade da equipe (Figura 13). Ao verificar os resultados da rodada 2 , os participantes têm a oportunidade de mudar as decisões, sem impactos nos custos e no prazo de execução do projeto. Dessa maneira, na rodada 3 (execução), pode-se confirmar as decisões da rodada 2 , ou alterar as escolhas. $\mathrm{Na}$ rodada 3, também, permite-se uma decisão incremental à rodada 2 , sobrepor em até $25 \%$ as atividades do projeto, porém, esta opção gera uma sobrecarga para a equipe e o aumento de custos devido às horas extras, portanto deve ser escolhida com bastante cautela. Nos resultados da rodada 3, a coluna de execução é disponibilizada e os gestores conseguem 
comparar o planejamento e a execução

(Figura15).

Figura 15 - Exemplo Resultado Rodadas 2 e 3

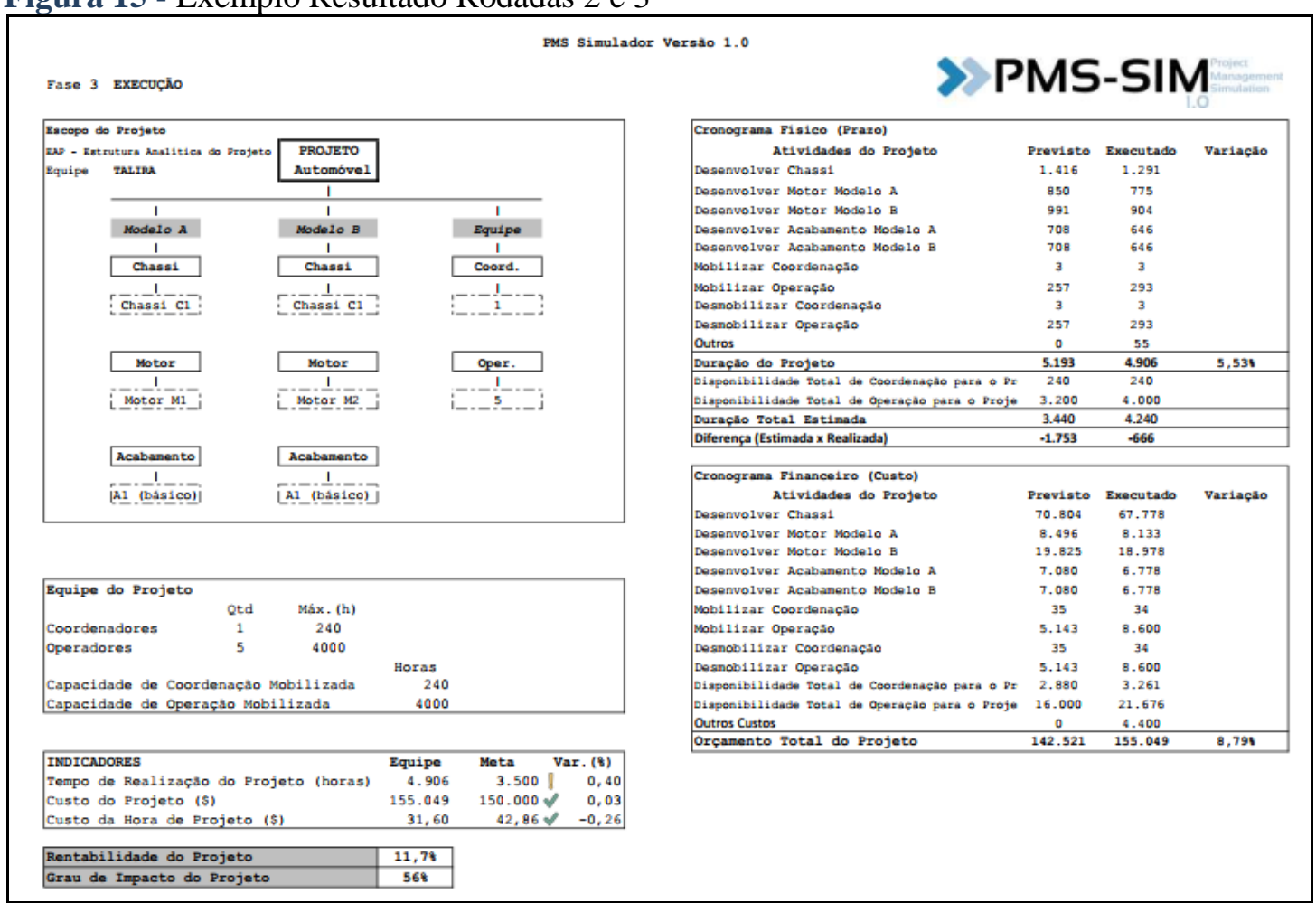

Fonte: Carreiro (2016).

Devido a limitações operacionais da dinâmica e ao fator didático de dividir o projeto, conforme as fases do ciclo de vida dos projetos, criou-se uma fase de controle, rodada três, que permite às equipes ajustarem suas decisões. É de fundamental importância salientar que nesta rodada as modificações terão custos e punições no prazo do projeto (Figura 16).

Figura 16 - Impactos Recursos, Prazo e Custo

\begin{tabular}{|c|c|c|c|c|}
\hline & $\begin{array}{c}\text { Contrataşão } \\
\text { Operador }\end{array}$ & $\begin{array}{l}\text { Demissão } \\
\text { Operador }\end{array}$ & $\begin{array}{l}\text { Contratação } \\
\text { Coordenador }\end{array}$ & $\begin{array}{l}\text { Demissão } \\
\text { Coordenador }\end{array}$ \\
\hline Prazo & $+55 \mathrm{~h}$ & $+70 \mathrm{~h}$ & $+5,5 \mathrm{~h}$ & $+7 \mathrm{~h}$ \\
\hline \multirow[t]{4}{*}{ Custo } & $+\$ 4.400,00$ & $+\$ 5.600,00$ & $+\$ 3.168,00$ & $+\$ 4.032,00$ \\
\hline & & Mudança Motor & \multicolumn{2}{|c|}{ Mudanģa Acabamento } \\
\hline & & + 100h cada & \multicolumn{2}{|c|}{ + 100h cada } \\
\hline & & $+30 \%$ do proj. motor & \multicolumn{2}{|c|}{$+20 \%$ do proj. acabamento } \\
\hline
\end{tabular}

Fonte: Elaborado pelos próprios autores (2020). 
Por fim, na rodada 5 (encerramento), os participantes devem criar e realizar uma apresentação final sobre a trajetória, as estratégias e as decisões. Nesta etapa final, o professor tem o papel de patrocinador do projeto.

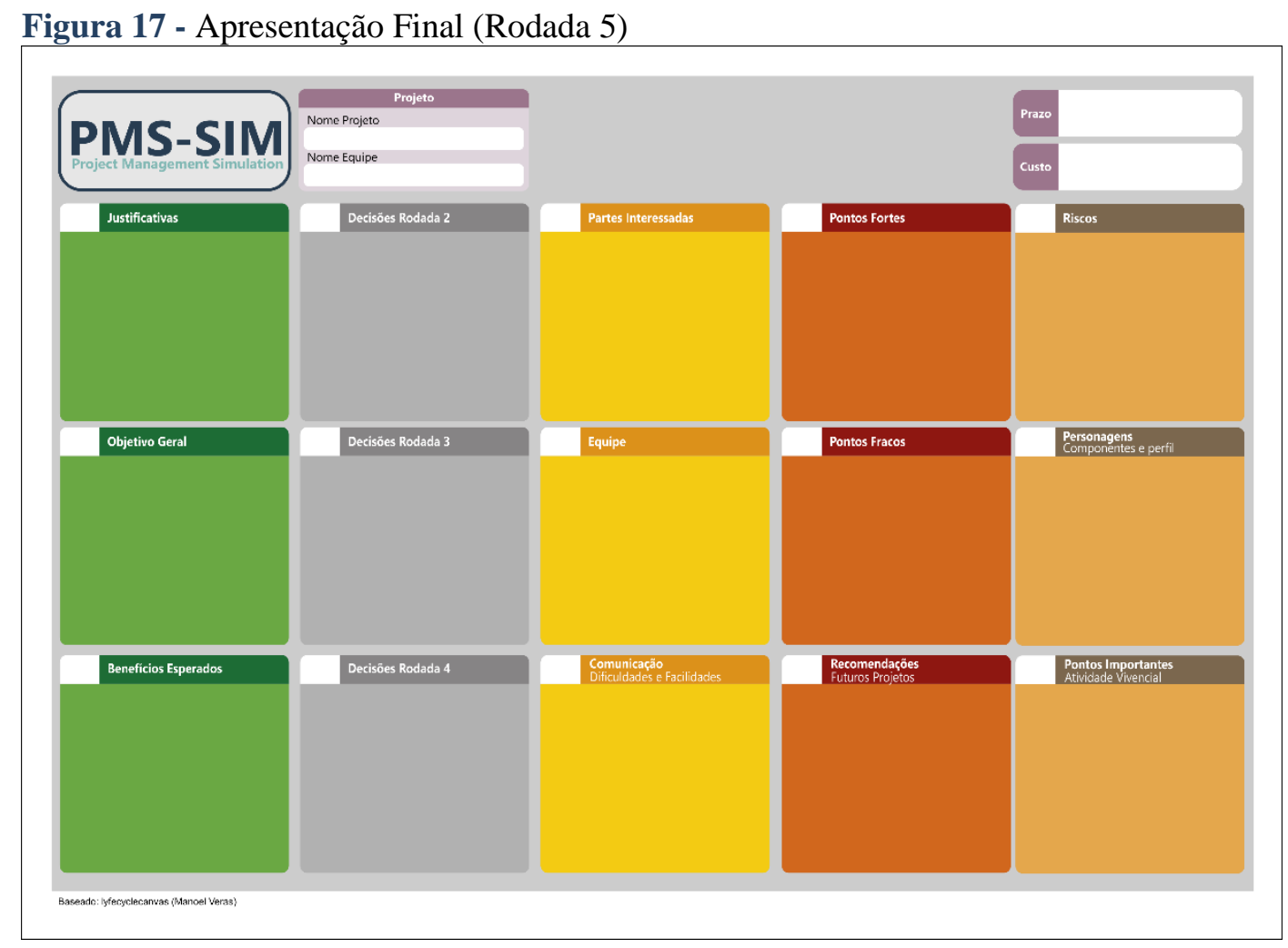

Fonte: Adaptado pelos próprios autores baseado em Medeiros, Almeida \& Oliveira (2018).

Esta rodada é fundamental para o aprendizado, pois as equipes indicam justificativas, objetivo geral, benefícios esperados, decisões das rodadas, quais são as partes interessadas do projeto, equipe, comunicação, pontos fortes e fracos, recomendações, riscos, personagens e pontos importantes da dinâmica para todos os participantes (Figura 16).

\section{Resultados obtidos e análise}

Quais as contribuições mais relevantes para os tópicos abordados no relato. Também deve ser incluída sua relevância para outros casos similares e que tipo de ensinamento profissional desta experiência relatada deve ser socializado na comunidade de profissionais.

\subsection{Análise do PMS-Sim com profissionais de gestão de projetos}

No primeiro estudo envolvendo o PMSSim, as opiniões dos profissionais de projetos revelaram a existência de distintas impressões quanto às contribuições na formação de competências. Percebem-se as características dos grupos de profissionais de acordo com o perfil associado, a experiência e o cargo, que determinam uma avaliação diferente. 
Os participantes indicaram que a vivência dinamizada pelo PMS-Sim promove contribuições na formação de competências em projetos. Os gerentes de projetos avaliaram a contribuição em níveis superiores aos demais, revelando que os mais experientes, e de maior nível hierárquico, percebem uma consistente contribuição na formação de competências. Esses profissionais, por já possuírem uma visão integrada da gestão de projetos, avaliaram a atividade proposta como um exercício que simula a gestão em projetos.

De maneira similar, os coordenadores, os especialistas e os analistas indicaram que a ACP promoveu contribuições moderadas nas três dimensões analisadas, cabendo destaque para contribuições acima da média, como: o gerenciamento das relações humanas na dimensão indivíduo (D1); o estímulo a mudanças e o estabelecimento de estratégias e de planos para os projetos na dimensão equipe (D2); na dimensão organização (D3), o destaque foi a capacidade de divulgação dos resultados do projeto.

Neste estágio do estudo, houve contribuições interessantes nos mais diversos aspectos para o campo da gestão de projetos e da aprendizagem gerencial, que podem ser assim listadas: (a) a descrição de uma atividade vivencial com profissionais da área de projetos e com o desenvolvimento de um simulador educacional específico para a capacitação; (b) a realização de uma aplicação prática de gestão de projetos, alinhando-se ao modelo de levantamento de competências exigidas para a carreira em projetos, e (c) a demonstração do potencial dos jogos de empresas para a formação na área de gestão de projetos.

No âmbito empresarial, possibilitou-se ilustrar o uso de simuladores em treinamentos para gestores de projetos, trazendo algo além da exposição do conhecimento (método convencional), promovendo a aplicação de suas competências num ambiente simulado.

\subsection{Adaptação acadêmica do PMS-Sim}

$$
\text { Para enfatizar alguns resultados }
$$
positivos da aplicação do PMS-Sim com o programa educacional no ambiente acadêmico, destaca-se o aspecto prático da disciplina que foi valorizado pelos alunos, com a consciência que esses momentos são importantes para a atuação profissional. Constata-se, também, que a parte teórica da disciplina, relacionada com as áreas de conhecimento de gestão de projetos como: comunicação, integração, gestão de pessoas, proporcionou a melhoria das competências das equipes. Esse aspecto, já evidenciado pela análise quantitativa, fez-se presente nos relatos dos discentes e do mediador.

Ficou em evidência como o desenvolvimento de habilidades no jogo de projetos pode ressignificar certas atitudes, de modo a buscar uma postura mais assertiva a cada interação. Os conflitos na equipe, de forma exemplificativa, revestem-se de aspectos positivos, pois a partir dessas situações, há todo um processo de convencimento que exige o preparo para poder argumentar. A essa 
dinâmica de busca de consenso está associada uma demonstração de maturidade.

$\mathrm{Na}$ análise das entregas, podem-se ressaltar os efeitos da aprendizagem, quer sejam de natureza cognitivos, sociais ou motivacionais. Alinhada com a aferição destes resultados, a condução da entrevista em profundidade com o mediador, bem como a dinâmica do grupo focal com os discentes, buscaram sondar se a prática vivencial despertou algum insight e qual o assunto relacionado ao PVGP foi objeto de maior interesse e que, eventualmente, motivaria o aprofundamento do mesmo.

Dentre os temas mais recorrentes, foram citados a comunicação, a capacidade de liderança, a coordenação de equipes, a integração e a motivação dos membros do grupo, a alocação de recursos, a exploração do planejamento, e a gestão do escopo do projeto. Percebe-se que foram abordados na parte teórica da disciplina de GP e estão relacionados, respectivamente, com as áreas de conhecimento de gestão de projetos como, comunicação, integração, gestão de pessoas, gestão do escopo, e assim por diante.

Em relação à aceitação do mediador ao método e ao jogo, o testemunho só veio a corroborar o entusiasmo inicial, acrescentando a decisão pela incorporação definitiva do PVGP à sua disciplina. Destacou-se que é importante utilizar o jogo para estimular pesquisas no ambiente simulado e não somente para o aprendizado em GP.

Na Figura 18, encontra-se um resumo com alguns aspectos observados na utilização do PMS-Sim no ambiente acadêmico, segmentado nas etapas de Entrada, Processo e Resultados, conforme modelo de avaliação de atividades com jogo de empresas (Kriz \&Hense, 2006).

Figura 18 - Contribuições do PMS-SIM no ambiente acadêmico

\begin{tabular}{|c|c|}
\hline Fase & Descrição \\
\hline Entrada & $\begin{array}{l}\text { - Na visão do mediador, o aspecto pragmático da disciplina de GP se alinha com a prática pedagógica do programa vivencial } \\
\text { com a utilização do jogo. } \\
\text { Aspecto positivo quanto à oportunidade de ter uma prática e a separação das equipes por critério outro que não a afinidade, } \\
\text { aspecto que reflete o que acontece no mercado corporativo. }\end{array}$ \\
\hline Processo & $\begin{array}{l}\text { - O jogo, em certa medida, propicia postura profissional aos alunos, aproximando-se da realidade, daí a importância para a } \\
\text { disciplina de GP. Outro aspecto é despertar áreas de afinidade na qual cada aluno virá a atuar. } \\
\text { Os conflitos são recorrentes no jogo outra característica da abordagem vivencial. } \\
\text { - A dinâmica para se chegar ao consenso sobre as decisões de cada jogada é uma demonstração de maturidade. A habilidade de } \\
\text { convencer se destaca nas equipes de melhor rendimento no jogo. } \\
\text { - O mediador destacou o ambiente de incerteza/competitividade proporcionado pelo jogo, aspecto usual à disciplina de GP, na } \\
\text { qual são rotineiras as atividades práticas. }\end{array}$ \\
\hline Resultado & $\begin{array}{l}\text { - O PVGP é multidisciplinar, fazendo o aluno caminhar pela gestão de pessoas, pela gestão de risco e perceber a interconexão } \\
\text { com a gestão de processos. Nesta última, perceber quais podem ser paralelizados. Unir uma ideia subjetiva teórica a algo que } \\
\text { é objetivo, prático, real e lógico. } \\
\text { Quanto aos efeitos organizacionais, destaca-se o despertar do participante para as áreas de interesse com as quis mais se } \\
\text { identifica dentro da equipe. A cada um no grupo atribuem-se tarefas de acordo com o seu perfil, sendo esta característica } \\
\text { própria de lideranças com habilidades de gestão. }\end{array}$ \\
\hline
\end{tabular}

Fonte: Elaborado pelos autores (2020). 
6.3 O PMS-Sim para ambientes de inovação
A evolução do PMS-Sim para

ambientes de inovação emergiu das análises das relações entre o processo de incubação e o gerenciamento de projetos, coadunandose com os achados na pesquisa com os gerentes das incubadoras (Guillen \& Veras, 2018). Referente ao modelo lógico de Kriz e Hense (2006), todos os doze fatores foram evidenciados nas falas dos participantes, como demonstrado na Figura 19.

Figura 19 - Fatores de Análise Segundo o Modelo Lógico de Kriz e Hense (2006)

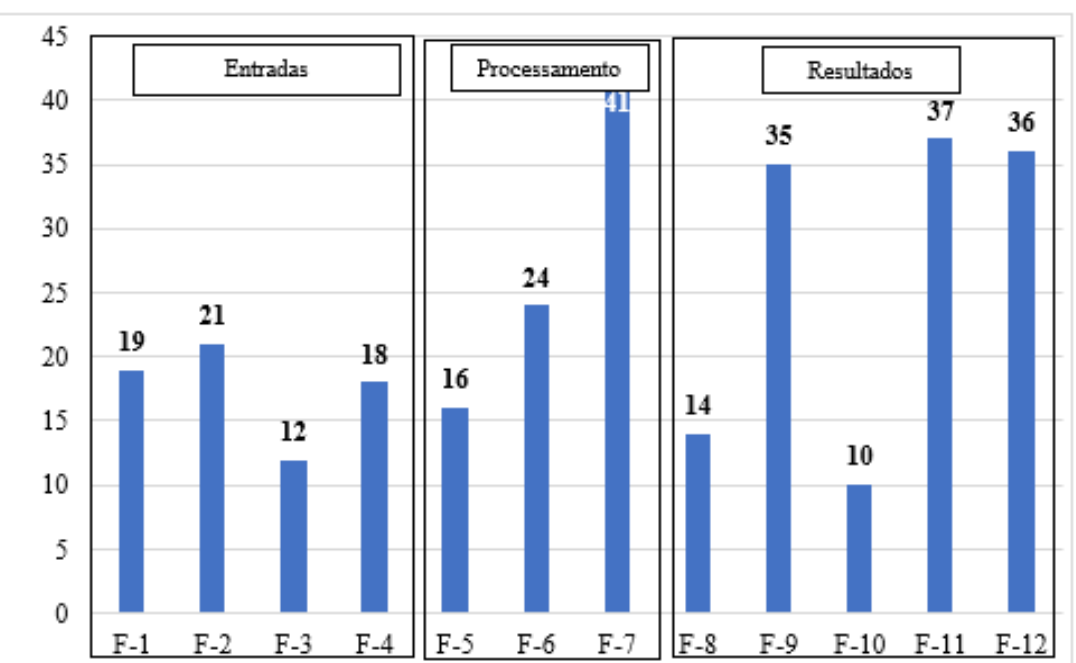

Legenda: F-1: Contexto; F-2: Qualidade do conteúdo do programa; F-3: Qualidade do jogo e do simulador; F-4: Atuação do mediador; F-5: Debriefing; F-6: Aprendizagem individual e social; F-7: Relação teoria e prática; F-8: Aceitação do método; F-9: Efeitos e/ou resultados organizacionais; F-10: Suporte ao participante F-11: Efeitos na aprendizagem (cognitivo, social, motivacional); F-12: Áreas de conhecimento em GP e o gerenciamento da empresa incubada.

Fonte: Elaborado pelos autores com base nos dados da pesquisa (2020).

As relações entre os processos de incubação e gestão de projetos apareceram, de alguma maneira, em 131 citações durante as entrevistas de levantamento de opinião. Analisando a Figura 19, nota-se aderência aos fatores de análise provenientes do modelo lógico de Kriz Hense (2006), mais especificamente com F-1: Contexto, justamente porque o processo de incubação faz parte da realidade dos participantes da vivência. Relaciona-se, também, com F-7: Relação Teoria e Prática, por aplicar conceitos teóricos de gestão de projetos em uma empresa incubada. Apresenta, em menor grau, aderência ao F-9: Efeitos e/ou Resultados Organizacionais. Outro fator que apresenta aderência a essas relações é F-12 Aprendizagem em Gestão de Projetos/Incubação, como pode ser observado nas considerações dos seguintes estudantes:

"Eu acredito que tenha relação. $\mathrm{Na}$ verdade, talvez não seja a mesma coisa, porque são coisas tipo... mas são muito próximas. Se tem uma linha ali é muito tênue. Então assim, gestão de projetos dentro da empresa incubada ... porque bem 
ou mal vai ser um projeto, é uma empresa? Ok! Mas é um projeto"(E9).

"porque tanto no projeto quanto na empresa incubada existem etapas pra você conseguir formar aquilo... é... etapa dentro do porquê você vai começar aquilo até o que aquilo vai trazer de bom, né? Isso no projeto e na empresa são muito importantes. Então saber o passo a passo de um projeto te ajuda no crescimento e estruturação inicial principalmente da empresa" (E2).

Esses achados apresentam alguma aglutinação com a teoria, no sentido de que os processos de gestão de projetos estão associados com as etapas do processo de incubação. Diante desses resultados, quando fatores do modelo lógico emergem, a partir de uma vivência com jogos de empresas, aglutinando gestão de projetos e incubação, evidencia-se que as impressões dos participantes parecem com as entrevistas com os gerentes das incubadoras (Neves et al., 2014; Neves \& Silva, 2016; Cruz, 2017; Souza, 2017; Guillen \& Veras, 2018).

Quanto à avaliação da qualidade do programa, segundo o modelo lógico de Kriz e Hense (2006), em termos de adequabilidade, considera-se o processo de criação do PVGP, a partir da análise do contexto, da utilização da técnica AHP para priorização dos elementos cruciais à vivência, a construção do material didático e de apoio, a realização do teste piloto da nova versão do PMS-Sim e a aplicação final. O levantamento permitiu avaliar, a partir das opiniões dos participantes, o conceito, design e a aplicação do programa em 250 citações. Isso significa dizer que algum elemento da vivência, em termos de qualidade e adequabilidade, tangenciou os fatores do modelo lógico.

As fragilidades da aplicação estão relacionadas ao funcionamento do PMS-Sim, cronograma e material didático, sequência lógico-didática, material de apoio, atuação do mediador e aprendizagem social. Embora em menor número de citações, as fragilidades representam pontos de melhoria para o programa e não prejudicaram sua aplicação. Ainda assim, o que se desenhou para o programa, a partir das entrevistas com os gerentes das incubadoras e das análises AHP, pôde ser visualizado durante a vivência.

\section{Considerações finais}

Ao longo do desenvolvimento do PMSSim e sua descrição longitudinal, a partir dos estágios de avaliação, pode-se evidenciar o rigor envolvido em seu projeto com a triangulação multimétodo adotada. Assim, a trajetória deste relato apresenta a relevância de um simulador educacional para a formação continuada em gestão de projetos em diferentes contextos e para além dos limites do planejamento em treinamentos convencionais.

Os resultados apresentados em cada estágio de avaliação do PMS-Sim permitem indicar o auxílio do sistema para a capacitação em gerenciamento de projetos, pois profissionais da área num ambiente organizacional relevaram a contribuição em vivenciar, de forma segura, as fases de um projeto; já em ambientes acadêmicos, alunos e docentes evidenciaram avanços do 
conhecimento em gestão de projetos a partir da adoção do PVGP numa disciplina.

Para ambientes de inovação, o PMSSim, alinhado ao PVGP, permitiu que o participante praticasse conhecimentos, habilidades e técnicas de gestão de projetos dentro de uma empresa incubada. Em linhas gerais, os participantes vivenciaram aspectos relacionados aos processos de gerenciamentos de projetos, ao tomarem decisão sob risco e incerteza, aprendendo a partir das relações de causa e de efeito em ambiente simulado.

Neste sentido, o PMS-Sim permite a formação em gestão de projetos, simulando o ambiente prático, envolvendo, além dos aspectos essenciais, também, a gestão de riscos e replanejamento de um projeto, integrando teoria e prática. Ele indica sua relevância de utilização, pois pode ser utilizado em diferentes ambientes (acadêmicos e empresariais).

Pode-se destacar a experiência em todas as fases de um projeto devido à possibilidade dos participantes vivenciarem a gestão de um projeto em todas as suas fases do ciclo de vida, também se identifica a integração das competências da gestão de projetos, pois ao longo do desenvolvimento, o PMS-Sim demonstrou a capacidade de integrar as metas de projetos numa organização com o desenvolvimento de equipe e as habilidades requeridas para gestor de projetos.

Em relação ao aprendizado social e as soft skills, pode-se perceber que, na vivência (jogo) dinamizada pelo PMS-Sim, os participantes conseguem desenvolver habilidades sociais como: comunicação, liderança e resolução de conflitos. Quanto aos ambientes de inovação, durante o jogo, tem-se a possibilidade de contribuir para a capacitação de gerentes de empresas incubadas com ferramentas de GP, o que pode propiciar a redução da mortalidade e aceleração de novos negócios e tecnologias.

Dentre os aspectos que limitaram o percurso do desenvolvimento e a avaliação do PMS-Sim, deve ser mencionado que o projeto descrito no caso educacional apresenta um acompanhado por meio de fases, porém não é possível um detalhamento de cada uma das atividades e pacotes de trabalho de maneira gradual. Outra limitação evidenciada foi a interface com os usuários e esta pode ser melhorada com maior interação e disponibilidade de relatórios específicos.

Já em relação ao método, deve-se mencionar que, apesar da utilização da triangulação multimétodo utilizada nas fases do desenvolvimento do simulador educacional apresentar inúmeras contribuições, percebe-se que o alinhamento para uma análise de causa e efeito nos participantes precisa ser desenvolvido com estudos e dados com maior padronização.

Diante das limitações identificadas, surgem as indicações de novos estudos para que os interessados neste tema de estudo possam avançar e complementar a evolução do simulador educacional e seus complementos.

Como sugestões de avanços, indica-se o desenvolvimento de um conjunto de tarefas 
mais detalhadas dentro de cada fase do ciclo de vida do projeto descrito no PMS-Sim. Assim com uma biblioteca de atividades com custos, prazos de execução, precedência e sequenciamento, o jogo de gestão de projetos ampliaria o uso de técnicas da área (ex. EVA, SCRUMM). Recomenda-se, também, a criação de recursos para o jogo de gestão de projetos e para o PMS-Sim que possibilitem o relacionamento com algum software profissional de gestão de projetos e até mesmo sua operacionalização via web.

Uma última, porém não definitiva recomendação, seria a validação sistematizada do PMS-Sim com o uso da análise de equações estruturais (SEM), técnica multivariada que tem como premissa um conjunto de relações, sendo cada uma com variáveis dependentes e independentes. Esta técnica permite a incorporação dos erros de medição no processo de estimação do modelo, estabelece relações de dependência inter-relacionadas e consegue definir suposições elaboradas com base no suporte teórico e incluí-las num modelo para exame de questões analíticas dos dados.

\section{Referências}

Bardin, L. (2016). Análise de conteúdo. São Paulo: Edições 70.

Bacich, L., \& Moran, J. (2018). Metodologias ativas para uma educação inovadora: uma abordagem teórico-prática. Penso Editora.

Barbosa, M. W., \& Rodrigues, C. de Á. (2020). Project Portfolio Management teaching: Contributions of a gamified approach. International Journal of Management Education, 18(2). https://doi.org/10.1016/j.ijme.2020.100388
Bell, A. (2016). The Development of a Conceptual Framework for Simulations in Project Management Education. Coventry University.

Bočková, K. H., Sláviková, G., \& Gabrhel, J. (2015). Game Theory as a Tool of Project Management. Procedia - Social and Behavioral Sciences, 213(1), 709-715.

Borrajo, F., Bueno, Y., De Pablo, I., Santos, B., Fernández, F., García, J., \& Sagredo, I. (2010). SIMBA: A simulator for business education and research. Decision Support Systems, 48(3), 498-506.

https://doi.org/10.1016/j.dss.2009.06.009

Bukvić, I. B., Buljubašić, I., \& Ivić, M. (2020). Project management education in Croatia : A focus on the IT sector needs PROJECT MANAGEMENT EDUCATION IN CROATIA : A FOCUS ON THE IT SECTOR NEEDS . Journal of Contemporary Management Issues. https://doi.org/https://doi.org/10.30924/mjcm i.25.1.14

Butzke, M. A., \& Alberton, A. (2017). Estilos de aprendizagem e jogos de empresa: a percepção discente sobre estratégia de ensino e ambiente de aprendizagem. REGE-Revista de Gestão, 24(1), 72-84. doi: doi.org/10.1016/j.rege.2016.10.003

Calderón, A., Ruiz, M., \& O’Connor, R. V. (2018). A serious game to support the ISO 21500 standard education in the context of software project management. Computer Standards and Interfaces, 60(May), 80-92. https://doi.org/10.1016/j.csi.2018.04.012

Carreiro, E. de L. P., \& Oliveira, M. A. (2015). Jogo de Empresas em Gestão de Projetos: aplicação em uma multinacional automobilística. Revista Pensamento Contemporâneo Em Administração, 9(4), 69. https://doi.org/10.12712/rpca.v9i4.593

Carreiro, E. de L. P., \& Oliveira, M. A. (2018). Análise da Implementação de um Programa Vivencial em Gestão de Projetos em Cursos Universitários. Revista de Gestão e Projetos, 09(02), 45-64. https://doi.org/10.5585/gep.v9i2.660

Carvalho, M. M., \& Rabequini Jr., R. (2017) Fundamentos em gestão de projetos: construindo competências para gerenciar projetos (4a ed.). São Paulo: Atlas.

Cicmil, S., \& Gaggiotti, H. (2018). Responsible forms of project management education: 
Theoretical plurality and reflective pedagogies. International Journal of Project Management, 36(1), 208-218. doi: doi.org/10.1016/j.ijproman.2017.07.005

Cruz, R. I. G. (2017). Processo de incubação de empresas de base tecnológica à luz da gestão de projetos: um estudo de casos múltiplos (Dissertação de mestrado, Centro de Ciências Sociais Aplicadas, Universidade Federal do Rio Grande do Norte). Recuperado de https://repositorio.ufrn.br/jspui/handle/12345 6789/24546

Denzin, N. K., Lincoln, Y. S. (2006). $O$ planejamento da pesquisa qualitativa: Teorias e abordagens. Porto Alegre, Bookman e Artmed.

Dias, J. A. S. (2016). Modelo de avaliação de um programa vivencial em gestão de projetos (Dissertação de Mestrado, Instituto de Ciências Humanas e Sociais, Universidade Federal Fluminense). Recuperado de https://app.uff.br/riuff/handle/1/6417

Drury-Grogan, M. L. (2014). Performance on agile teams: Relating iteration objectives and critical decisions to project management success factors. Information and Software Technology, 56(5), 506-515.

Eder, S., Conforto, E. C., Amaral, D. C., \& Silva, S. L. D. (2015). Diferenciando as abordagens tradicional e ágil de gerenciamento de projetos. Production, 25(3), 482-497.

https://doi.org/10.1590/S010365132014005000021.

Guillen, R. I., \& Veras, M. (2018). Processo de incubação de empresas de base tecnológica à luz da gestão de projetos: Um estudo de casos múltiplos. Revista de Gestão e Secretariado, 9(2), 126-157. doi: https://doi.org/10.7769/gesec.v9i2.760

Hornstein, H. A. (2015). The integration of project management and organizational change management is now a necessity. International Journal of Project Management, 33(2), 291-298. doi: https://doi.org/10.1016/j.ijproman.2014.08.0 05

Kolb, A. Y., Kolb, D. A., Passarelli, A., \& Sharma, G. (2014). On becoming an experiential educator: The educator role profile. Simulation \& Gaming, 45(2), 204-
234. doi:

https://doi.org/10.1177/1046878114534383

Kriz, W. C., \& Hense, J. U. (2006). Theoryoriented evaluation for the design of and research in gaming and simulation. Simulation \& Gaming, 37(2), 268-283. doi: https://doi.org/10.1177/1046878106287950

Lacruz, A. J., \& Américo, B. L. (2018). Influência do debriefing no aprendizado em jogos de empresas: um delineamento experimental. Brazilian Business Review, 15(2), 192-208. doi: doi.org/10.1590/S151970772003000100006

LAGOS. (2020). Laboratório de Gestão Organizacional Simulada. Nossa história [online]. Disponível em: <http://lagos.sites.uff.br/nossa-historia/>. Acessado 29 de Agosto, 2020.

Law, K. M. (2019). Teaching project management using project-action learning (PAL) games: A case involving engineering management students in Hong Kong. International Journal of Engineering Business Management, 11(1), 1-7. doi: https://doi.org/10.1177/1847979019828570

Liu, J. W., Ho, C. Y., Chang, J. Y., \& Tsai, J. C. A. (2019). The role of Sprint planning and feedback in game development projects: Implications for game quality. Journal of Systems and Software, 154, 79-91.

Medeiros, B. C., da Silva Araújo, V. F., de Almeida, M. K., \& Oliveira, S. (2018). Life Cycle Canvas (LCC): Um modelo visual para a gestão do ciclo de vida do projeto. Revista de Gestão e Projetos-GeP, 9(1), 87-101.

Morillo, C., 2018a. Pessoa Pensando. [image] Available at: < https://www.pexels.com/ptbr/foto/adulto-ambiente-de-trabalho-area-detrabalho-atividade-1181676/> [Accessed 10 December 2020].

Morillo, C., 2018b. Pessoa Ajudando no Ambiente de trabalho [image] Available at: $<$ https://www.pexels.com/pt-br/foto/adultoajudar-ambiente-de-trabalho-apoio1181472/> [Accessed 10 December 2020].

Neves, S. M., Da Silva, C. E. S., Salomon, V. A. P., Da Silva, A. F., \& Sotomonte, B. E. P. (2014). Risk management in software projects through knowledge management techniques: cases in Brazilian incubated technology-based firms. International Journal of Project Management, 32(1), 125138. doi: 
https://doi.org/10.1016/j.ijproman.2013.02.0 07

Neves, S. M., \& Silva, C. E. S. D. (2016). Gestão de riscos aplicada a projetos de desenvolvimento de software em empresas de base tecnológica incubadas: revisão, classificação e análise da literatura. Gestão \& Produção, 23(4), 798-814. doi: https://doi.org/10.1590/0104-530x472-15

Ojiako, U., Ashleigh, M., Chipulu, M., \& Maguire, S. (2011). Learning and teaching challenges in project management. International Journal of Project Management, 29(3), 268-278.

Oliveira, M. A.; Teodoro, P. (2013). Manual do Simulador de Gestão de Projetos (PMSSIM). Rio de Janeiro, RJ, Fundação Biblioteca Nacional. N. de Registro 602.412.

Patah, L. A.; Carvalho, M. M.; Biazzin, C. ; Ferreira, F. C.; Vasconcellos, L. H. R. (2016). Construindo pontes entre ensino e a prática da gestão de projetos. MundoPM (Curitiba), v. 12, p. 75-83.

Perides, M. P. N., Vasconcellos, E. P. G. de, \& Vasconcellos, L. (2020). A gestão de mudanças em projetos de transformação digital: estudo de caso em uma organização financeira. Revista de Gestão e Projetos, 11(1), 54-73. https://doi.org/10.5585/gep.v11i1.16087

Piacquadio, A., 2020. Pessoa Dizendo Não. [image] Available at: <https://www.pexels.com/pt-br/foto/mulherde-pe-retrato-oculos-3762802/> [Accessed 10 December 2020].

Picciotto, R. (2019). Towards a 'New Project Management'movement? An international development perspective. International Journal of Project Management. Publicação eletrônica antecipada. doi: https://doi.org/10.1016/j.ijproman.2019.08.0 02

PMI - Project Management Institute (2017). Um guia do conhecimento em gerenciamento de projetos (Guia PMBOK). (6a ed.). Pennsylvania: Project Management Institute.

Reich, B. H., Gemino, A., \& Sauer, C. (2014). How knowledge management impacts performance in projects: An empirical study. International Journal of Project Management, 32(4), 590-602. doi: doi.org/10.1016/j.ijproman.2013.09.004
Richelieu, A., 2020. Liderança. [image] Available at: <https://www.pexels.com/ptbr/foto/bandeira-norte-americana-bandeirados-estados-unidos-afro-americano-mulherafro-americana-4427626/> [Accessed 10 December 2020].

Rokooei, S., Goedert, J. D., \& Najjar, L. (2017). Enhancing Construction Project Management Education by Simulation. Journal of Professional Issues in Engineering Education and Practice, 143(4), 1-9. doi: doi.org/10.1061/(ASCE)EI.19435541.0000329

Santos-Souza, H. R., \& Oliveira, M. A. (2019). O Uso de Jogos de Empresas em Diferentes Níveis Educacionais: Integração, Prática e Pesquisa Envolvendo Estudantes de Graduação e Pós-Graduação em Administração. Administração: Ensino e Pesquisa, 20(1), 147-183. doi: https://doi.org/10.13058/raep.2019.v20n1.12 $\underline{90}$

Sauaia, A. C. A. (2013). Laboratório de gestão: simulador organizacional, jogo de empresas e pesquisa aplicada. Editora Manole.

Sauaia, A. C. A., \& Zerrenner, S. A. (2009). Jogos de empresas e economia experimental: um estudo da racionalidade organizacional na tomada de decisão. Revista De Administração Contemporânea, 13(2), 189209. https://doi.org/10.1590/S141565552009000200003

Schmitz, L. C., Alperstedt, G. D., Van Bellen, H. M., \& Schmitz, J. L. (2015). Limitações e Dificuldades Na Utilização Da Abordagem Experiencial no ensino De Gerenciamento De Projetos Em Um Curso De Graduação Em Administração. Administração: Ensino e Pesquisa, 16(3), 537. http://doi.org/10.13058/raep.2015.v16n3.283

Silva, R. F., \& de Melo, F. C. L. (2016). Modelos híbridos de gestão de projetos como estratégia na condução de soluções em cenários dinâmicos e competitivos. Revista Brasileira de Gestão e Desenvolvimento Regional, 12(3).

Souza, E. R. (2017). Uma análise das metodologias de gerenciamento de projetos em incubadoras de base tecnológica e parques tecnológicos no estado de São Paulo: um estudo de casos múltiplos. (Dissertação de Mestrado, Programa de Mestrado Profissional em Administração - 
Gestão de Projetos, Universidade Nove de Julho, São Paulo). Recuperado de: http://bdtd.ibict.br/vufind/Record/NOVE_e7 49501b503a23d9537d10aa132a18ce

Souza, H. R. S (2019). Programa de Aprendizagem Vivencial em Gestão De Projetos para Incubadoras de Empresas. Dissertação de Mestrado, Instituto de Ciências Humanas e Sociais, Universidade Federal Fluminense). Recuperado de https://app.uff.br/riuff/handle/1/13217

UFF. Universidade Federal Fluminense. (2020). Apresentação. [online]. Disponível em: <http://www.uff.br/?q=apresentacao> Acessado 29 de Agosto, 2020.

Vargas, L. (2016). Gerenciamento Ágil de Projetos em Desenvolvimento de Software: Um Estudo Comparativo sobre a Aplicabilidade do Scrum em Conjunto com PMBOK e/ou PRINCE2. Revista de Gestão e Projetos, 7(3), 48-60. doi:https://doi.org/10.5585/gep.v7i3.398

Vieira, G. L. S., \& Antoniolli, P. D. (2018). Adoção de Boas Práticas em Gerenciamento de Projetos: Estudo em Empresas Brasileiras. Revista IPTEC, 6(1), 78-93. DOI https://doi.org/10.5585/iptec.v6i1.136. 